\title{
The Efficient IPO Market Hypothesis: Theory and
}

\section{Evidence}

\author{
Kevin R. James and Marcela Valenzuela*
}

*James (corresponding author), k.james1@lse.ac.uk, Systemic Risk Centre, London School of Economics; Valenzuela, mavalenb@uc.cl, Universidad de Chile (DII) and Pontificia Universidad Catolica de Chile. We thank Cindy Alexander, Jon Danielsson, Giulia Fantini, Charles Goodhart, Evgeny Lyandres, Robert Macrae, David Reiffen, Peter Sinclair, Claudia Robles-Garcia, Redis Zaliauskas, and seminar participants at the LSE, SEC, and the University of Swansea for helpful comments and discussions. We thank the anonymous referee and the Editor Jarrad Harford for suggestions that enabled us to substantially improve our analysis and exposition. We thank Katerina Karamani for research assistance. The support of the Economic and Social Research Council (ESRC) in funding the SRC is gratefully acknowledged [grant number ES/R009724/1]. Valenzuela acknowledges the support of Fondecyt Project No. 1190477 and Instituto Milenio ICM IS130002. The views in this paper are solely the responsibility of the authors. 


\begin{abstract}
We derive the optimal underwriting method and the quantitative IPO pricing rule that this method implies in a market with informational frictions consisting of fully rational banks, issuers, and investors. In an efficient IPO market, an issuer's expected initial return will be determined entirely by the combination of this pricing rule and issuer fundamentals. Applying this rule, we find that we can explain the quantitative magnitude of the principal aspects of the time-series and cross-sectional variation in IPO average initial returns. We conclude that the IPO market is efficient.
\end{abstract}

Keywords: Initial Public Offerings, Underwriters, IPO Underpricing, Efficient Markets Hypothesis

\title{
I. Introduction
}

In the IPO market sophisticated issuers with considerable sums at stake acquire underwriting services from a large number of capable and highly competitive investment banks. In such a market, we conjecture that banks will use the optimal underwriting method to take firms public and that IPO offer prices (and so average initial returns) will be determined entirely by issuer fundamentals given the pricing rule implied by that underwriting method. We label this conjecture the Efficient IPO Market Hypothesis (EIMH). In this paper we develop and test the EIMH.

We begin by deriving the optimal underwriting method in a market with informational frictions consisting of fully rational banks, issuers, and investors. ${ }^{1}$ The

\footnotetext{
${ }^{1}$ Our analysis builds upon Gondat-Larralde and James (2008).
} 
agency conflict and/or behavioral factors that provide the point of departure for much of the post-DotCom Boom research on IPOs play no role in our analysis. ${ }^{2}$ Our analysis yields a quantitative pricing rule that enables us to compute the numerical value of the average initial return implied by issuer fundamentals in an efficient IPO market $\left(\bar{R}_{\text {EIM }}^{*}\right)$ for a TEST portfolio of IPOs given the return distribution of a completely independent CONTROL portfolio of IPOs. ${ }^{3}$ If our theory is correct, then the observed average initial return on a TEST portfolio will equal that portfolio's $\bar{R}_{\mathrm{EIM}}^{*}$.

We test our theory by seeing if we can resolve the principal average initial return $(\bar{R})$ anomalies in the IPO literature, to wit: i) the high $\bar{R}$ on IPOs during the DotCom Boom of $1999 / 2000$; and ii) the high $\bar{R}$ on Tech IPOs relative to the $\bar{R}$ on NonTech IPOs (Loughran and Ritter (2002), Ritter and Welch (2002), Ljungqvist and Wilhelm (2003), Loughran and Ritter (2004), Kang and Lowery (2014)). ${ }^{4}$

To carry out this test, we divide our sample along a Tech (TECH) or NonTech (NTECH) cross-sectional dimension and a Boom (BOOM) or PostBoom (PBOOM) time-series dimension (where the PostBoom period consists of the years 2001/2016). We then sort sample IPOs into four TEST portfolios: BOOM/TECH (B/T), BOOM/NTECH

\footnotetext{
${ }^{2}$ This recent IPO literature largely follows the agency conflict/behavioral factor path suggested by Ritter and Welch (2002).

${ }^{3}$ That is, all of our $\bar{R}_{\text {EIM }}^{*}$ predictions are out of sample predictions.

${ }^{4}$ For example, Ljungqvist and Wilhelm (2003) write that "it strains belief that even collectively this body of theory [informational frictions with rational agents] can account for the profound change in market behavior [during the DotCom boom]", and Ritter and Welch (2002) conclude their survey by observing that "we believe that future explanations [of underpricing] will need to concentrate on agency conflicts and share allocation issues on one hand and behavioral explanations on the other hand...the challenge for such theories will be to explain the dramatic variations in underpricing".
} 
(B/NT), PBOOM/TECH (PB/T), and PBOOM/NTECH (PB/NT). Using PBOOM IPOs as our CONTROL, we find that $\bar{R}_{\mathrm{EIM}}^{*}$ on $\mathrm{B} / \mathrm{T}$ IPOs is $75.30 \%$ and that $\bar{R}_{\mathrm{EIM}}^{*}$ on $\mathrm{B} / \mathrm{NT}$ IPOs is $26.74 \%$. The observed $\bar{R}$ on these IPOs is $76.74 \%$ and $28.55 \%$, respectively. Using BOOM IPOs as our CONTROL, we find that $\bar{R}_{\mathrm{EIM}}^{*}$ on PB/T IPOs is $20.92 \%$ and that $\bar{R}_{\mathrm{EIM}}^{*}$ on PB/NT IPOs is $10.97 \%$. The observed $\bar{R}$ on these IPOs is $17.07 \%$ and $11.76 \%$ respectively. That is, we find that the combination of the optimal pricing rule we derive for an efficient IPO market and issuer fundamentals yields precise and accurate predictions for the quantitative magnitude of both the cross-sectional and time-series variation in Tech and NonTech IPO average initial returns.

The strong empirical support that we find for the implications of our theory therefore implies that issuer fundamentals rather than agency conflict and/or behavioral factors determine IPO offer prices.

We believe that the IPO market functions in the way that it does because of three key features. First, we assume that an IPO failure is very costly for both a bank and an issuer and hence that issuers choose between banks that can ensure that their IPO will be a success. ${ }^{5}$ Second, in order for an IPO to be a success, a bank must place shares of highly uncertain value with both potentially informed $(Y)$ and uninformed $(N)$ investors. ${ }^{6}$ In

\footnotetext{
${ }^{5}$ This strong "No Failure" assumption simplifies our analysis, but we show in Section II.B that weakening this assumption does not alter our results.

${ }^{6}$ Our reasoning on this point is as follows: if banks knew that investors were definitely uninformed, then the optimal method to take a firm public would be to hold a sealed bid auction for the IPO shares. Yet, Jagannathan, Jirnyi, and Sherman's (2015) examination of the competition between underwriting methods in over 50 countries finds that sealed bid auctions never emerge as the dominant underwriting method if underwriters are free to choose alternatives. It follows that sealed bid auctions are not (in practice) the optimal underwriting method, and this result in turn implies that at least some investors do potentially
} 
particular, we assume that a $Y$ investor has the option to lemon-dodge, that is, to expend a minimal amount of costly effort and avoid participating in an IPO if its share value $V$ is less than its offer price $P$. Lemon-dodging therefore enables a $Y$ investor to avoid an IPO's downside risk. ${ }^{7}$ And third, since neither a bank nor an issuer knows the issuer's offer price at the time the issuer chooses a bank to take them public, we assume that market value maximizing banks compete for underwriting mandates on the basis of their expected price of underwriting services.

A $Y$ investor selected at random to participate in an IPO will always find it profitable to lemon-dodge as by doing so they can avoid participating in IPOs with a negative return (even if the bank underprices IPO shares on average). Since a bank's IPOs will fail with positive probability if $Y$ investors do lemon-dodge, a bank must devise an underwriting method such that $Y$ investors choose not to lemon-dodge. We refer to this requirement as the No Lemon-Dodging Constraint or NLDC.

A bank can successfully deal with the NLDC by block-booking its IPOs (Kenney and Klein (1983), Gondat-Larralde and James (2008)). A block-booking bank enters into a repeat game with a stable coalition of $Y$ investors in which the bank: i) underprices its IPO shares on average; ii) preferentially selects coalition investors to participate in its IPOs; and iii) ejects any investor who does lemon-dodge from its coalition. ${ }^{8}$ The

possess private information.

${ }^{7}$ An IPO's downside risk equals the absolute value of its expected return setting all positive return realizations to 0 .

${ }^{8}$ Our assumption that banks enter into a repeat game with a coalition of investors is consistent with the empirical findings on IPO share allocation by Cornelli and Goldreich (2001), Gondat-Larralde and James (2008), Grullon, Underwood, and Weston (2014), Brown and Kovbasyuk (2016), Krigman and Jeffus (2016), 
combination of on-average underpricing and preferential selection creates a profit stream for an investor the bank invites into its coalition, and a coalition investor who chooses to lemon-dodge loses this profit stream. The bank then sets offer prices such that an investor finds coalition membership (and so purchasing IPO shares at the offer price without lemon-dodging) more profitable than lemon-dodging once.

To derive the pricing rule that block-booking implies, we begin by positing that issuers choose between banks on the basis of a bank's expected price of underwriting services per $\$ 1$ of expected market value sold in the IPO. A bank's expected price of underwriting services equals the sum of expected fees and expected underpricing. A bank can therefore split the equilibrium price of its services between fees and underpricing as it chooses without affecting the probability that it wins a mandate.

Given that a bank collects all of the fees but must share the money that underpricing leaves on the table with investors (Goldstein, Irvine, and Puckett (2011)), a block-booking bank will choose the maximum expected offer price for its IPOs consistent with satisfying the NLDC. In other words, a bank minimizes expected underpricing to the extent possible so as to maximize income from fees given an equilibrium expected price of underwriting services. An IPO's fundamental offer price is therefore the offer price implied by this condition.

Expected offer price maximization subject to the NLDC implies that a bank sets offer prices to equalize downside risk across its offerings. To see why, suppose that offer prices in all future periods are fixed and consider the offer price a bank will choose for a given IPO in the current period. If a bank block-books, then the profit a coalition investor and Jenkinson, Jones, and Suntheim (2017). 
expects to obtain by remaining in the bank's coalition (coalition profit) is independent of the profit they expect to obtain by lemon-dodging on the current IPO (lemon-dodging profit). But, lemon-dodging profit on the current IPO increase as that IPO's offer price increases (or, in other words, an IPO's downside risk increases with its offer price). So, a bank will increase the current IPO's offer price to the point where a $Y$ investor's lemon-dodging profit on that IPO given that offer price just equals the fixed coalition profit. Since lemon-dodging profit is equal to IPO's downside risk, the downside risk on the current IPO given its offer price must equal this fixed coalition profit for any IPO the bank underwrities. It follows that a bank sets offer prices to equalize downside risk across its IPOs.

If banks do set offer prices to equalize downside risk across their offerings, then we can compute $\bar{R}_{\mathrm{EIM}}^{*}$ on a TEST portfolio as follows. We first estimate the equilibrium level of downside risk from a completely independent CONTROL portfolio. Then, we adjust TEST IPO offer prices by a scalar until the downside risk on TEST IPOs given those adjusted offer prices equals the equilibrium level of downside risk. The average initial return on TEST IPOs in an efficient market is then the average initial return on those IPOs calculated with these adjusted offer prices. We therefore test our theory by seeing if the $\bar{R}_{\text {EIM }}^{*}$ we compute for a portfolio of TEST IPOs is equal to the observed average initial return on those IPOs.

While we focus on explaining the cross-sectional and time-series variation in underpricing for IPO types, our analysis also leads to a reinterpretation of two other key aspects of the IPO market, namely: i) the within type cross-sectional variation in $\bar{R}$ known as the Partial-Adjustment Effect ((Benveniste and Spindt (1989) and Hanley (1993)); and 
ii) investor kickbacks (Loughran and Ritter (2002, 2004), Reuter (2006), Nimalendran, Ritter, and Zhang (2007), and Goldstein et al. (2011)). Consider each in turn.

The Partial-Adjustment Effect refers to the following empirical pattern. If the IPO process generates bad news about an IPO's value, the bank lowers that IPO's offer price (relative to its initial offer price estimate) to the point where the IPO's expected initial return is positive but small; on the other hand, if the IPO process generates good news about an IPO's value, the bank raises that IPO's offer price but only to a point where the expected return on that IPO is positive and large. It therefore appears that the offer price of an IPO only partially reacts to any good news that the IPO process generates.

In our model, this empirical pattern arises as follows: i) each IPO type consists of a low value $\beta$ isotype and a high value $\alpha$ isotype; ii) issuers have MaxiMin preferences; and iii) banks set offer prices to equalize downside risk across IPO types (not isotypes). Banks therefore set $\beta$ IPO offer prices at their maximum feasible level and set $\alpha$ IPO offer prices at the level that brings about downside risk equalization across IPO types. It follows that $\beta$ IPO offer prices are higher and $\alpha$ IPO offer prices are lower than they would be if banks set offer prices to equalize downside risk across each isotype independently.

Crucially, though, one must measure the magnitude of these MaxiMin effects by comparing the observed $\bar{R}$ on $\alpha$ or $\beta$ IPOs to what it would have been if downside risk equalization held for each isotype independently (rather than for the IPO type as a whole) and not by comparing the $\bar{R}$ on $\alpha$ IPOs to that on $\beta$ IPOs. We show in the Appendix that: i) the MaxiMin effect does lead to an increase in $\beta$ IPO offer prices during the Boom, causing $\bar{R}$ on these IPOs to fall by between $10.28 \%$ and $14.55 \%$; and that ii) the MaxiMin 
effect is near zero for $\alpha$ IPOs during the Boom and for all IPOs in the PostBoom period. ${ }^{9}$ So, the magnitude of the $\bar{R}$ on $\alpha$ IPOs is not due to $\alpha$ IPO offer prices only partially adjusting to their full standalone equilibrium value.

In common with the agency conflict approach to the IPO market, we assume that banks profit by collecting spreads from issuers and (effectively) kickbacks from investors who compensate the bank in some way in exchange for being invited to purchase on-average underpriced IPO shares. Our theory implies that, in the case of coalition investors, the money that underpricing appears to leave on the table is just sufficient to ensure that block-booking works. Consequently, our analysis predicts that coalition investors will not pay kickbacks to the banks that invite them to participate in an offering. In the case of non-coalition investors, on the other hand, the money that underpricing appears to leave on the table really is money left on the table. Our analysis therefore predicts that these investors will pay kickbacks.

Consistent with these predictions, Goldstein et al.'s (2011) thorough investigation of investor kickbacks finds that: i) coalition (or, in their terminology, regular) investors do not pay kickbacks; and that ii) non-coalition (or, in their terminology, transitory) investors do pay kickbacks. In other words, banks do not underprice IPOs in order to collect kickbacks, they collect kickbacks (from non-coalition investors) because they must underprice IPOs. ${ }^{10}$

\footnotetext{
${ }^{9}$ Since $\alpha$ IPOs outnumber $\beta$ IPOs by a considerable margin, the increase on $\beta$ IPO offer prices during the Boom entails only a very small decrease on $\alpha$ IPO offer prices.

${ }^{10}$ If banks can collect kickbacks from non-coalition investors when bringing a firm public, then the profit a bank obtains by winning a mandate increases. Hence, banks will compete more intensely to win mandates, and this more intense competition will in turn lead to lower underwriting fees. It follows that a regime in which banks could not collect kickbacks from non-coalition investors would increase the price of underwriting
} 
We note one caveat that arises from our assumption that banks are homogeneous. We show empirically that this assumption holds along the underwriter prestige dimension (Carter and Manaster (1990), Carter, Dark, and Singh (1998), Loughran and Ritter (2004)). That is, we find that high prestige and low prestige underwriters use the same pricing rule. But, our equilibrium does depend upon a repeat game mechanism, and so one might naturally expect to find that high volume banks have a considerable competitive advantage over low volume banks. However, we find in unreported analysis that high volume and low volume banks also use the same pricing rule. This result is a puzzle given our model as it stands, and we therefore plan to explore competition between heterogenous banks in future work.

\section{Previous Literature}

Our analysis belongs to the rational agent/informational frictions branch of the IPO literature. As in Benveniste and Spindt (1989) and Benveniste and Wilhelm (1990), we posit that banks use a repeat game mechanism to overcome informational frictions. We build upon Kenney and Klein's (1983) general analysis of block-booking and the application of the block-booking idea to the IPO market by Gondat-Larralde and James (2008). Gondat-Larralde and James examine the case of a single bank underwriting an exogenous stream of IPOs and find that the bank can maximize IPO proceeds by setting offer prices to equalize downside risk across its offerings. We extend Gondat-Larralde and James' analysis by deriving the full market equilibrium with competing banks and

services for issuers. 
endogenous spreads, offer prices, and investor kickbacks.

The rational agent/informational frictions approach to analyzing the IPO market has fallen out of favor due to its inability to provide an adequate explanation for the time-series and cross-sectional variation in IPO average initial returns. Consequently, most of the PostBoom literature has looked to non-fundamental factors such as agency conflicts and behavioral biases to explain this variation. We cite the principal papers in this agency conflict/behavioral bias branch of the literature above.

We completely agree with the idea that it may be useful to explore the possible role that agency conflicts and/or behavioral biases play in determining IPO offer prices if one finds a significant gap between observed average initial returns and those implied by issuer fundamentals. Our disagreement with the agency conflict/behavioral bias literature arises from our different approaches to calculating $\bar{R}_{\mathrm{EIM}}^{*}$. We derive an IPO pricing rule that enables us to accurately compute $\bar{R}_{\mathrm{EIM}}^{*}$. The agency conflict/behavioral bias papers instead estimate $\bar{R}_{\mathrm{EIM}}^{*}$ using reduced form pricing rules based on issuer characteristics. ${ }^{11}$ Our analysis suggests that these reduced form pricing rules do not adequately proxy for the downside risk equalization pricing rule we derive and so produce a large apparent gap between observed average initial returns and $\bar{R}_{\mathrm{EIM}}^{*}$ where (at least according to our analysis) no such gap exists.

We organize our analysis as follows. In Section II we derive the optimal underwriting method in an efficient IPO market. In Section III we derive an empirical test for our conjecture that IPO offer prices are determined by issuer fundamentals given the

\footnotetext{
${ }^{11}$ Butler, Keefe, and Kieschnick (2014) identify 48 issuer characteristics (selected on largely atheoretical grounds) that have been used (in various combinations) in these reduced form pricing rules.
} 
optimal underwriting method. In Section IV we describe the IPO sample we use for our analysis. We carry out our empirical tests in Section V and we present our conclusions in Section VI. We include an appendix with additional material on the market equilibrium, our empirical approach, and the MaxiMin effect.

\section{IPO Pricing in an Efficient Market}

We analyze a bank's choice of underwriting method in a market with informational frictions consisting of fully rational banks, issuers, and investors. We: i) describe our set-up; ii) derive a bank's optimal pricing rule, investor kickback rates, gross spread, and share allocation method given a market equilibrium; and iii) show that the market equilibrium exists and examine the empirical implications of that equilibrium.

\section{A. Set-Up and Assumptions}

The market consists of $Q_{U}$ identical banks, type $Y$ and $N$ investors, and issuers. An issuer is of type $\tau$ and variety $\eta$, with $\eta \in\{\alpha, \beta\}$. We refer to a $\tau / \eta$ combination as an isotype.

\section{Timing}

In period $t_{0}$ each bank $u$ simultaneously specifies: i) a gross spread $S_{u}$; ii) a kickback rate $\kappa_{Y, u}$ and $\kappa_{N, u}$ for each investor type; and iii) an offer price for each IPO isotype $P_{\tau, \eta, u}$.

In each period $t, t \geq t_{1}$, an issuer undertakes an IPO. The IPO process consists of the following actions: 
$a_{1}$ : the issuer chooses a bank to take their firm public;

$a_{2}$ : the bank and investors can observe the issuer's type and its initial expected offer price of $P_{\tau, u}$;

$a_{3}$ : the bank invites specific investors it chooses into the pool of eligible investors in exchange for a kickback (which can be 0);

$a_{4}: Y$ investors in the investor pool decide whether or not to acquire private information on the issuer's value;

$a_{5}$ : the IPO process reveals the issuer's variety $\eta$;

$a_{6}$ : the bank sets the issuer's offer price as a function of its type and variety;

$a_{7}$ : the bank makes the eligible investors a take it or leave it offer to purchase IPO shares at the offer price;

$a_{8}$ : all investors decide whether or not they wish to participate given the firm's type, variety, offer price, and their information on its market value; and

$a_{9}$ : if the investors do choose to participate then the IPO succeeds and if they do not the IPO fails. ${ }^{12}$ If the IPO is a success, trading begins and reveals the market value $V$ of the issuer's shares.

\footnotetext{
${ }^{12}$ Though we do not model it here, allowing an issuer to withdraw its IPO at anytime before the bank sets the issuer's offer price and offers shares to investors would not affect our analysis.
} 


\section{Issuers}

Each issuing firm consists of a single project with an expected value of $\$ 1$ and a single infinitely divisible share (that is, an offer price in our analysis is the offer price per expected dollar of market value). An issuer is of type $\tau$ with probability $\phi_{\tau}$, $\tau=\{1, \ldots, \mathcal{T}\}$, with $\sum_{\tau} \phi_{\tau}=1$. For each IPO type, proportion $\sigma_{\tau, \eta}$ are of variety $\eta$, with $\eta \in\{\alpha, \beta\}$ and with $\sigma_{\tau, \alpha}+\sigma_{\tau, \beta}=1$. The market value of the $t^{t h}$ period issuer is $V_{\tau, \eta, t}^{*}$, which is an iid realization of random variable $V_{\tau, \eta}$ (we use an "*" to denote the optimal value of a choice variable or a specific value of a non-choice variable). Each $V_{\tau, \eta}$ distribution has the following properties (which are common knowledge): i) $V_{\tau, \eta}$ is continuously distributed on $\{0, \infty\}$; ii) $\mathrm{E}\left[V_{\tau, \eta}\right]=\bar{V}_{\tau, \eta}$; iii) $\bar{V}_{\tau, \alpha}>\bar{V}_{\tau, \beta}$; and iv) $V_{\tau, \eta} \sim \Psi_{\tau, \eta}$ (pdf: $\psi_{\tau, \eta}$ ).

Since a variety $\alpha$ project has a higher expected market value than a variety $\beta$ project for a given IPO type, it is good news for an issuer if the offering process reveals that a project is of variety $\alpha$. We assume that $P_{\tau, \alpha, u}^{*}>\bar{V}_{\tau, \beta, u} \geq P_{\tau, \beta, u}^{*}$, where $P_{\tau, \eta, u}^{*}$ is the equilibrium offer price on a $\tau / \eta$ IPO.

We assume that an IPO failure is very costly for issuers and that issuers can attempt to go public just once. We further assume that issuers have MaxiMin preferences and so seek to maximize the minimum amount they raise from their IPO. Consequently, issuers choose a bank from the set of banks with an underwriting method that: i) ensures that the bank's IPOs succeed; and ii) produces offer prices such that $P_{\tau, \beta, u}$ equals its maximum feasible value for all $\tau$. We refer to underwriting methods with these properties as valid methods.

From the set of banks with valid underwriting methods, the probability that an 
issuer chooses a given bank $z$ is a function of $z$ 's relative price of underwriting services. If all banks with valid underwriting methods have the same price of underwriting services, then an issuer chooses at random between them.

\section{Investors}

Each investor acts to maximize their profit, and each investor invests a constant amount of one unit in each IPO in which they participate. An investor is either potentially informed (type $Y$ ) or uninformed (type $N$ ). We refer to investors generically with an $\iota$ subscript. We assume that a bank must place a proportion $\sigma_{Y}\left(\sigma_{N}\right)$ of the shares of each IPO with $Y(N)$ investors, with $\sigma_{Y}+\sigma_{N}=1$. Investors cannot act strategically (e.g., coordinate their actions to form a buyer cartel).

Individual investors are identifiable and their type is observable, and all investors are identical in all respects except their access to private information on an IPO's value. In particular, all investors are risk-neutral and have a discount parameter of $\gamma_{\iota}$, and all investors can observe an IPO's type in $a_{2}$ and its variety in $a_{5}$. Investors only participate in an offering if they expect a non-negative return.

In addition, a $Y$ investor has the option to expend a minimal amount of costly effort in $a_{4}$ to put themselves into a position to know if $V_{\tau, \eta, t}<P_{\tau, \eta, u}$ in $a_{8}$ (that is, at the point when they make their participation decision). We refer to this behavior as lemon-dodging, and we assume that an investor's decision to lemon-dodge is observable by the bank in $a_{9}{ }^{13}$ A lemon-dodging investor declines to participate in an IPO if they find that $V_{\tau, \eta, t}$ is

\footnotetext{
${ }^{13}$ As an investor's decision to decline to participate is observable, assuming that the bank can observe an investor's decision to lemon-dodge directly simplifies our analysis but does not change our results.
} 
less than $P_{\tau, \eta, u}$ (if an investor would instead choose to participate in these circumstances, they do not lemon-dodge in the first place).

Given that $V_{\tau, \eta}$ is distributed on $\{0, \infty\}$, an IPO will fail with positive probability if $Y$ investors choose to lemon-dodge. Since the bank must place IPO shares with $Y$ investors in order for an IPO to succeed, the bank must design an underwriting method such that $Y$ investors choose not to lemon-dodge. We refer to this requirement as the No Lemon-Dodging Constraint or the NLDC.

A bank must also place shares with $N$ investors. An $N$ investor has no private information on an IPO's value and will only participate if they expect to obtain a non-negative return. It follows that a bank must set offer prices such that $P_{\tau, \eta} \leq \bar{V}_{\tau, \eta}$.

If $Y$ investors do not lemon-dodge, then neither the investors nor the bank has any private information on an issuer's market value. Hence, the maximum feasible offer price on a $\beta$ IPO is $\bar{V}_{\tau, \eta}$. Since banks must set the offer price of a $\beta$ IPO at the maximum feasible level, each bank chooses optimal offer prices $P_{\tau, \alpha, u}^{*}$ and $P_{\tau, \beta, u}^{*}$ such that

$$
P_{\tau, \alpha, u}^{*} \leq \bar{V}_{\tau, \alpha} \text { and } P_{\tau, \beta, u}^{*} \approx \bar{V}_{\tau, \beta} \forall \tau
$$

We refer to equation (1) as the Pricing Constraint. ${ }^{14}$ A valid underwriting method is one that satisfies both the NLDC and the Pricing Constraint.

\footnotetext{
${ }^{14}$ Empirically, banks do slightly underprice $\beta$ IPOs on average ( $\bar{R}$ on these IPOs is about $4 \%$ ). In common with the rest of the literature on the partial-adjustment effect, we do not model the determinants of this element of underpricing. We conjecture that banks must in practice offer $N$ investors a small positive expected return in order to induce them to participate rather than simply a non-negative return. In our empirical analysis we assume that the fundamental offer price on a $\beta$ IPO is equal to its observed offer price.
} 


\section{Banks}

Each risk neutral bank $u, u=1 \ldots U$, devises a valid underwriting method and

chooses: i) a set of offer prices $\vec{P}_{u}$, with $\vec{P}_{u}=\left\{P_{1, \alpha, u}, P_{1, \beta, u}^{*}, \ldots, P_{\mathcal{T}, \alpha, u}, P_{\mathcal{T}, \beta, u}^{*}\right\}$; ii) a gross spread $S_{u}$; and iii) kickback rates $\kappa_{Y, u}$ and $\kappa_{N, u}$ in $t_{0}$ to maximize its $t_{0}$ market value $M_{u}$, with

$$
M_{u}=\sum_{t} \gamma_{u}^{t} \phi_{w, u, t} \bar{\pi}_{u}
$$

where $\gamma_{u}$ is the bank discount parameter (which is the same for all banks), $\phi_{w, u, t}$ is the probability that the bank wins an underwriting mandate in period $t$, and $\bar{\pi}_{u}$ is the expected profit a bank obtains given that it wins a mandate. Each bank acts in a purely intermediary capacity and cannot make side-payments to either investors or issuers. We assume that a bank does not incur any direct costs when underwriting an issuer.

A bank obtains profit by collecting gross spreads from issuers and kickbacks from investors. Consider each revenue stream in turn.

Each bank chooses a gross spread $S_{u}$ in $t_{0}$ and so obtains $S_{u} P_{\tau, \eta, u}$ in fee income for each issuer it takes public.

A bank can require that investors who wish to participate in the offering kickback a proportion of the expected money that underpricing leaves on the table to the bank before the bank includes them in the eligible investor pool. The expected amount of money that underpricing leaves on the table for a $\tau$ IPO is $\lambda_{\tau, u}$, with

$$
\lambda_{\tau, u}=\bar{V}_{\tau, u}-P_{\tau, u}
$$


$P_{\tau, u}$ is the expected offer price on a $\tau$ IPO, with

$$
P_{\tau, u}=\sigma_{\tau, \alpha} P_{\tau, \alpha, u}+\sigma_{\tau, \beta} P_{\tau, \beta, u} .
$$

A bank's kickback rate for investors of type $\iota$ equals $\kappa_{\iota, u}$, with $0 \leq \kappa_{\iota, u} \leq \kappa_{\mathrm{MAX}}<1$. A bank therefore obtains $K_{\tau, u}$ in kickbacks given that it is underwriting a $\tau$ IPO, with

$$
K_{\tau, u}=\left(\sigma_{Y} \kappa_{Y, u}+\sigma_{N} \kappa_{N, u}\right) \lambda_{\tau, u}<\lambda_{\tau, u} .
$$

Combining revenue from fees and kickbacks, a bank expects to obtain a profit of $\pi_{\tau, u}$ when underwriting a $\tau$ IPO, with

$$
\pi_{\tau, u}=S_{u} P_{\tau, u}+\left(\sigma_{Y} \kappa_{Y, u}+\sigma_{N} \kappa_{N, u}\right) \lambda_{\tau, u} .
$$

Since an issuer must choose an underwriter before either the issuer or the underwriter knows its type, the probability that a mandate that a bank wins is of type $\tau$ is just equal to the probability that an issuer is of type $\tau$. It follows that

$$
\bar{\pi}_{u}=\sum_{\tau} \phi_{\tau} \pi_{\tau, u}=S_{u} \bar{P}_{u}+\left(\sigma_{Y} \kappa_{Y, u}+\sigma_{N} \kappa_{N, u}\right) \bar{\lambda}_{u}
$$

where

$$
\begin{aligned}
\bar{P}_{u} & =\sum_{\tau} \phi_{\tau} P_{\tau, u}, \\
\bar{V}_{u} & =\sum_{\tau} \phi_{\tau} \bar{V}_{\tau, u},
\end{aligned}
$$


and

$$
\bar{\lambda}_{u}=\sum_{\tau} \phi_{\tau} \lambda_{\tau, u}=\bar{V}_{u}-\bar{P}_{u}
$$

A bank's expected price of underwriting services is then $\omega_{u}$, with

$$
\omega_{u}=S_{u} \bar{P}_{u}+\bar{\lambda}_{u}
$$

We assume that the market reaches a symmetric Nash equilibrium in which each bank $j$ chooses its equilibrium price of underwriting services $\omega_{j}^{*}$ such that

$$
\omega_{j}^{*}=\Omega^{*} \forall j
$$

where $\Omega^{*}$ is the market equilibrium price of underwriting services.

\section{B. The IPO Market with Block-Booking Banks}

In this section we assume that the market is in equilibrium and examine an individual bank's choice of underwriting method.

If the market is in equilibrium, then $\omega_{u}=\Omega^{*}$. In this case a bank's probability of winning a mandate in each period is $1 / Q_{U}$ and the probability that a mandate the bank wins is of type $\tau$ equals the probability that an issuer is of type $\tau\left(\phi_{\tau}\right)$. A bank's task is to choose the valid underwriting method that maximizes its market value given $\Omega^{*}$ and this flow of IPOs.

Given that $\omega=\Omega^{*}$, a bank can split its price of underwriting services between expected fees and expected underpricing as it wishes without affecting the probability that 
it wins a mandate (since we are dealing with a single bank, we will generally drop the bank index $u$ in our exposition). So, we begin our analysis of a bank's choice of underwriting method by examining how it chooses between spreads and kickbacks.

Proposition 1 Within the constraints imposed by its choice of a valid underwriting method, a bank maximizes the expected offer price (minimizes expected underpricing) of its IPOs so as to maximize expected fees.

Proof: See Appendix.

Intuitively, this result follows from the fact that while issuers are indifferent between a dollar of fees and a dollar of underpricing, a bank keeps all of the underwriting fees but it must share the money that underpricing leaves on the table with investors. A bank therefore sets offer prices to maximize $\bar{P}$ subject to the constraints imposed by its choice of valid underwriting method.

We conjecture that the valid underwriting method a bank chooses is block-booking. We now examine the pricing constraints that this choice imposes.

Proposition 2 Block-booking is a valid underwriting method. A block-booking bank: i) underprices its IPOs on average; ii) allocates IPO shares by entering into a repeat game with a coalition of $Y$ investors and by selecting $N$ investors at random; iii) sets the $Y$ investor kickback rate to 0 ; and iv) sets the $N$ investor kickback rate to its maximum possible value $\kappa_{M A X}$.

To be valid, a bank's underwriting method must enable it to successfully place shares of each IPO type with both $Y$ and $N$ investors. Consider each investor type in turn. 
To successfully place shares with $Y$ investors, a bank must devise an underwriting method such that $Y$ investors choose to purchase IPO shares at the offer price for each IPO type (which we refer to as buying sight-unseen) rather than lemon-dodge.

A $Y$ investor makes the buy sight-unseen/lemon-dodge decision knowing an IPO's type but not its isotype and after paying a kickback (if any) to be included in the investor pool. So, at the decision point, a $Y$ investor who buys sight-unseen expects to obtain a profit of $\pi_{Y, \tau, \mathrm{SU}}$, with

$$
\pi_{Y, \tau, \mathrm{SU}}=\sigma_{\alpha} \pi_{Y, \tau, \alpha, \mathrm{SU}}+\sigma_{\beta} \pi_{Y, \tau, \beta, \mathrm{SU}}
$$

where

$$
\pi_{Y, \tau, \eta, \mathrm{SU}}=\frac{1}{P_{\tau, \eta}} \int_{0}^{\infty}\left(V_{\tau, \eta}-P_{\tau, \eta}\right) \psi_{\tau, \eta} \mathrm{d} V
$$

$$
=\int_{0}^{\infty} \frac{V_{\tau, \eta}-P_{\tau, \eta}}{P_{\tau, \eta}} \psi_{\tau, \eta} \mathrm{d} V=\bar{R}_{\tau, \eta}
$$

and where $\bar{R}$ is an IPOs expected initial return. It is useful to express $\pi_{Y, \tau, \eta, \mathrm{SU}}$ (and so $\bar{R}$ ) as a combination of downside risk $\delta$ and upside risk $v$, with

$$
\pi_{Y, \tau, \eta, \mathrm{SU}}\left[P_{\tau, \eta}\right]=-\delta_{\tau, \eta}\left[P_{\tau, \eta}\right]+v_{\tau, \eta}\left[P_{\tau, \eta}\right]
$$

where

$$
\delta_{\tau, \eta}\left[P_{\tau, \eta}\right]=\left|\int_{0}^{P_{\tau, \eta}} \frac{V_{\tau, \eta}-P_{\tau, \eta}}{P_{\tau, \eta}} \psi_{\tau, \eta} \mathrm{d} V\right|
$$


and

$$
v_{\tau, \eta}\left[P_{\tau, \eta}\right]=\int_{P_{\tau}}^{\infty} \frac{V_{\tau, \eta}-P_{\tau, \eta}}{P_{\tau, \eta}} \psi_{\tau, \eta} \mathrm{d} V
$$

We note that $\frac{\partial \delta}{\partial P}>0$. It follows that

$$
\pi_{Y, \tau, \mathrm{SU}}=-\left(\sigma_{\alpha} \delta_{\tau, \alpha}+\sigma_{\beta} \delta_{\tau, \beta}\right)+\left(\sigma_{\alpha} v_{\tau, \alpha}+\sigma_{\beta} v_{\tau, \beta}\right)
$$

$$
=-\delta_{\tau}\left[P_{\tau, \alpha}, P_{\tau, \beta}^{*}\right]+v_{\tau}\left[P_{\tau, \alpha}, P_{\tau, \beta}^{*}\right]
$$

If an investor lemon-dodges, they avoid participating if $V_{\tau, \eta, t}<P_{\tau, \eta}$. Consequently, a lemon-dodging investor avoids an IPO's downside risk and so obtains an expected profit of $\pi_{Y, \tau, L}$, where

$$
\pi_{Y, \tau, L}=v_{\tau}
$$

Obviously,

$$
\pi_{Y, \tau, L}=v_{\tau}>-\delta_{\tau}+v_{\tau}=\pi_{Y, \tau, \mathrm{SU}}
$$

Equation (13) implies that a $Y$ investor selected at random will always choose to lemon-dodge for any offer price the bank sets and hence that a bank cannot eliminate lemon-dodging by simply underpricing its shares.

A bank can eliminate lemon-dodging by block-booking its IPOs. To do so, a bank 
enters into a repeat game with a coalition of $Q_{\chi} Y$ investors in which: i) the coalition investors agree to buy sight-unseen rather than to lemon-dodge; and ii) the bank makes coalition membership valuable by underpricing its IPO shares on average and selecting its $Y$ investors from its coalition. To enforce this arrangement, the bank ejects any investor who does lemon-dodge from its coalition. The bank then sets offer prices such that a coalition investor finds that the profits of the block-booking arrangement $\left(\pi_{Y, \tau, \mathrm{BB}}\right)$ exceeds the profits of lemon-dodging once.

The profit a $Y$ investor expects to obtain by participating in the bank's block-booking arrangement equals the sum of the profit the investor obtains by buying the current IPO sight-unseen and the expected coalition profits of $\pi_{Y, \chi}$ that follow from participating in on-average underpriced IPOs in the future. So,

$$
\pi_{Y, \tau, \mathrm{BB}}=\pi_{Y, \tau, \mathrm{SU}}+\pi_{Y, \chi}
$$

We assume that a bank picks the optimal number of investors to form its coalition, ${ }^{15}$ that it selects investors at random from its coalition for each IPO it underwrites, and that each investor invests 1 unit in each IPO in which they participate. ${ }^{16}$

\footnotetext{
${ }^{15}$ Coalition management is not the focus of our analysis here, and we abstract from such issues by assuming that investors cannot act strategically. However, we would expect banks to build some redundancy into their coalitions so that, for example, no one investor is in a position to obstruct an IPO's success by refusing to participate at the last minute.

${ }^{16}$ That is, the analysis below is done on a per-unit of investment basis, and for convenience we assume that each investor invests one unit in each IPO in which they participate. Merging investors together (so that one investor invests multiple units) would not change any of the results.
} 
Hence, each coalition investor expects a coalition profit of

$$
\pi_{Y, \chi}=\frac{1}{Q_{\chi}} \frac{1}{Q_{U}} \sum_{t} \gamma_{\iota}^{t}\left(1-\kappa_{Y}\right)(\bar{V}-\bar{P})=\sigma_{\chi}\left(1-\kappa_{Y}\right)(\bar{V}-\bar{P})
$$

where $\sigma_{\chi}=1 / Q_{\chi}{ }^{1} / Q_{U}{ }^{1 /\left(1-\gamma_{\iota}\right)}$.

An investor will refrain from lemon-dodging if the profit they obtain by remaining in the bank's coalition exceeds the profit of lemon-dodging once. We can therefore write the NLDC as

$$
\pi_{Y, \tau, \mathrm{BB}} \geq v_{\tau}=\pi_{Y, \tau, L}
$$

implying that (from equations (14) and (15))

$$
\bar{P} \leq \bar{V}-\frac{1}{\sigma_{\chi}} \frac{1}{1-\kappa_{Y}} \delta_{\tau}
$$

Given that the bank acts to maximize $\bar{P}$, it follows that equation (17) will be binding and that the bank will set $\kappa_{Y}=0$ (that is, it does not make sense to underprice by more than necessary to get block-booking to work and then collect only a portion of that extra underpricing back in the form of investor kickbacks). As equation (17) must hold for all IPO types, we can simplify the NLDC to

$$
\bar{P} \leq \bar{V}-\frac{\operatorname{Max}[\vec{\delta}]}{\sigma_{\chi}}
$$

where $\vec{\delta}=\left\{\delta_{1}\left[P_{1, \alpha}, P_{1, \beta}^{*}\right], \ldots, \delta_{\mathcal{T}}\left[P_{\mathcal{T}, \alpha}, P_{\mathcal{T}, \beta}^{*}\right]\right\}$. 
The fact that a bank underprices its IPO shares on average follows immediately from the NLDC. If $P_{\tau, \eta}>0$ for any IPO type, then $\delta_{\tau}>0$ and so Max $[\vec{\delta}]>0$, implying that $\bar{P}<\bar{V}$.

A bank must also place shares with $N$ investors who cannot lemon-dodge. If a bank block-books, then all $N$ investors know that $Y$ investors do not lemon-dodge and hence that $\mathrm{E}\left[V_{\tau, \eta, t}\right]=\bar{V}_{\tau, \eta}$. It follows that an $N$ investor selected at random will participate if

$$
\pi_{N, \tau, \eta}=\frac{1}{P_{\tau, \eta}}\left(\bar{V}_{\tau, \eta}-P_{\tau, \eta}\right)\left(1-\kappa_{N}\right) \geq 0
$$

Since a bank must set offer prices such that $P_{\tau, \eta} \leq \bar{V}_{\tau, \eta}$ and since $\kappa_{N} \leq \kappa_{\mathrm{MAX}}<1$, equation (19) holds for any possible value of $\kappa_{N}$ and any feasible set of offer prices. Since a bank's profits obviously increase as kickbacks increase, a bank allocates IPO shares to $N$ investors by selecting them at random and setting $\kappa_{N}=\kappa_{\mathrm{MAX}}$.

So, a block-booking bank can successfully place shares of all IPO types with both $Y$ and $N$ investors. Block-booking is therefore a valid underwriting method.

A block-booking bank chooses the pricing rule that maximizes $\bar{P}$ subject to satisfying the NLDC. We now derive that pricing rule.

Proposition 3 A block-booking bank sets offer prices to equalize downside risk across its IPOs. The combination of block-booking and the downside risk equalization pricing rule maximizes bank market value, implying that block-booking is the optimal underwriting method.

In line with the intuition we discuss in the Introduction, suppose that a bank does set offer prices such that $\delta_{\tau}=\delta_{\text {DRE }}$ for all $\tau$ (where DRE stands for Downside Risk 
Equalization). In this case, we can rewrite the NLDC as

$$
\bar{P}\left[\delta_{\mathrm{DRE}}\right] \leq \bar{V}-\frac{\delta_{\mathrm{DRE}}}{\sigma_{\chi}}
$$

Obviously, the left side of equation (20) increases and the right side decreases as $\delta$ increases. It follows that there exists a maximum feasible value of $\delta$, which we denote by $\delta_{\mathrm{DRE}}^{*}$, such that $\bar{P}\left[\delta_{\mathrm{DRE}}^{*}\right]=\bar{V}-\delta_{\mathrm{DRE}}^{*} / \sigma_{\chi}$, with $0<\bar{P}\left[\delta_{\mathrm{DRE}}^{*}\right]<\bar{V}$. Denote this value of $\bar{P}$ by $\bar{P}_{\mathrm{DRE}}^{*}$ and the implied $P_{\tau, \alpha}$ for each IPO type by $P_{\tau, \alpha, \mathrm{DRE}}^{*}$.

Now consider any alternative set of offer prices $\left\{P_{1, \alpha, \mathrm{ALT}}, \ldots, P_{\mathcal{T}, \alpha, \mathrm{ALT}}\right\}$ such that

$$
\bar{P}_{\mathrm{ALT}}=\sum_{\tau} \phi_{\tau}\left(\sigma_{\tau, \alpha} P_{\tau, \alpha, \mathrm{ALT}}+\sigma_{\tau, \beta} P_{\tau, \beta}^{*}\right) \geq \bar{P}_{\mathrm{DRE}}^{*}
$$

If $\bar{P}_{\mathrm{ALT}} \geq \bar{P}_{\mathrm{DRE}}^{*}$, then there must exist at least one IPO type $j$ such that $P_{j, \alpha, \mathrm{ALT}}>P_{j, \alpha, \mathrm{DRE}}^{*}$. Consequently, $\delta_{j}\left[P_{j, \alpha, \mathrm{ALT}}\right]>\delta_{\mathrm{DRE}}^{*}$ (given that $P_{\tau, \beta, \mathrm{DRE}}^{*}=P_{\tau, \beta, \mathrm{ALT}}=\bar{V}_{\tau, \beta}$ due to the Pricing Constraint). But, these relationships and equations (18) and (20) then imply that

$$
\bar{P}_{\mathrm{ALT}} \geq \bar{P}_{\mathrm{DRE}}^{*}=\bar{V}-\frac{\delta_{\mathrm{DRE}}^{*}}{\sigma_{\chi}}>\bar{V}-\frac{\delta_{j, \mathrm{ALT}}}{\sigma_{\chi}} .
$$

That is, there does not exist any alternative set offer prices $\vec{P}_{\mathrm{ALT}}$ such that $\bar{P}_{\mathrm{ALT}} \geq \bar{P}_{\mathrm{DRE}}^{*}$ and that prevent $Y$ investors from lemon-dodging. Consequently, the combination of block-booking and the downside risk equalization pricing rule produces the highest expected offer price that also satisfies the NLDC. Since a bank's underwriting method must satisfy the NLDC (as we model the IPO market) and a bank's market value increases with 
$\bar{P}$, it follows that the block-booking/downside risk equalization pricing rule maximizes bank market value and hence that block-booking is the optimal underwriting method.

Our proof that the downside risk equalization pricing rule is optimal rests upon the assumption that issuers choose between banks that can guarantee IPO success. While this assumption does simplify our analysis, the downside risk equalization rule is in fact optimal unless issuers and banks would be willing to tolerate a significant failure risk. To see why, note that the period $t$ IPO will succeed with certainty if a bank block-books and if $P_{\tau, \alpha, t} \leq P_{\tau, \alpha}^{*}$. But, if an issuer insists upon an offer price of $P_{\tau, \alpha}^{*}+\epsilon$, then $Y$ investors will lemon-dodge rather than buy sight-unseen. In this case the probability of an IPO failure increases discontinuously to PROB[Fail], with

$$
\operatorname{PROB}[\text { Fail }]=\sigma_{\tau, \alpha} \operatorname{PROB}\left[V_{\tau, \alpha}<P_{\tau, \alpha}^{*}\right]+\sigma_{\tau, \beta} \operatorname{PROB}\left[V_{\tau, \beta}<P_{\tau, \beta}^{*}\right]>0 .
$$

That is, issuers do not face a continuous trade-off between offer price and IPO failure probability (where one could imagine different issuers picking different offer price/failure probability combinations). Instead, issuers must choose between the block-booking offer price/guaranteed IPO success combination or a slightly higher offer price/substantial risk of IPO failure combination. Market behavior suggests that issuers prefer the block-booking option.

Proposition 4 The block-booking pricing rule (given issuer preferences) determines a unique optimal offer price for each isotype $P_{\tau, \eta}^{*}$ and unique optimal gross spread $S^{*}$.

We assume that issuer MaxiMin preferences lead a block-booking bank to set $\beta$ IPO 
offer prices at their maximum feasible value, implying that

$$
P_{\tau, \beta}^{*}=\bar{V}_{\tau, \beta} \forall \tau
$$

A bank therefore sets $P_{\tau, \alpha}$ to ensure that $\delta_{\tau}=\delta_{\mathrm{DRE}}^{*}$. Recalling that

$$
\delta_{\tau}=\sigma_{\tau, \alpha} \delta_{\tau, \alpha}\left[P_{\tau, \alpha}\right]+\sigma_{\tau, \beta} \delta_{\tau, \beta}\left[P_{\tau, \beta}^{*}\right]
$$

it follows that

$$
P_{\tau, \alpha}^{*}=P_{\tau, \alpha}: \delta_{\tau, \alpha}\left[P_{\tau, \alpha}\right]=\frac{\delta_{\mathrm{DRE}}^{*}-\sigma_{\tau, \beta} \delta_{\tau, \beta}\left[P_{\tau, \beta}^{*}\right]}{\sigma_{\tau, \alpha}}
$$

A bank's price of underwriting services $\Omega$ equals the sum of expected fees $(\bar{S} \bar{P})$ and the money it leaves on the table due to underpricing $(\bar{V}-\bar{P})$ (equation $(4)$ ). Assuming that the market is in equilibrium, we find that

$$
\Omega^{*}=S \bar{P}_{\mathrm{DRE}}^{*}+\left(\bar{V}-\bar{P}_{\mathrm{DRE}}^{*}\right)
$$

Solving for the equilibrium value of $S$ yields

$$
S^{*}=\frac{\Omega^{*}-\left(\bar{V}-\bar{P}_{\mathrm{DRE}}^{*}\right)}{\bar{P}_{\mathrm{DRE}}^{*}} .
$$

Proposition 4 completes our analysis of IPO pricing, kickbacks, spreads, and share allocation for a block-booking bank given a market equilibrium price of underwriting 
services.

\section{The Market Equilibrium}

We now establish that the market equilibrium exists and derive the key properties of that equilibrium.

Proposition 5 A market equilibrium price of underwriting services exist.

Proof: See Appendix.

In this equilibrium we find that:

Proposition 6 The downside risk of an IPO of type $\tau$ underwritten by a bank $u$ will equal the market equilibrium level of downside risk $\Delta^{*}$ for all IPO types and all banks. This result and the Pricing Constraint then enable us to derive the fundamental offer price (given that banks block-book) on $\tau / \alpha$ IPOs of $P_{\tau, \alpha, E I M}^{*}$ and the fundamental offer price on

$\tau / \beta$ IPOs of $P_{\tau, \beta, E I M}^{*}$. The expected initial return on $\tau$ IPOs of $\bar{R}_{\tau, E I M}^{*}$ in an efficient IPO market equals the expected initial return on those IPOs given that offer prices equal fundamental offer prices.

Given that a market equilibrium price of underwriting services exists, that all banks are identical, and that banks compete for underwriting mandates on the basis of their expected price of underwriting services, it follows that all banks choose the same offer price for each isotype: that is,

$$
P_{\tau, \eta, j}^{*}=P_{\tau, \eta, k}^{*}
$$


for all IPO isotypes $\{\tau, \eta\}$ and all banks $\{j, k\}$. Consequently, we shall now drop the bank index from offer price expressions.

The combination of downside risk equalization across IPO types for a given bank and offer price equalization for a given IPO isotype across banks then implies that

$$
\delta_{g, j}\left[P_{g, \alpha}^{*}, P_{g, \beta}^{*}\right]=\delta_{h, k}\left[P_{h, \alpha}^{*}, P_{h, \beta}^{*}\right]=\delta_{\mathrm{DRE}, j}^{*}=\delta_{\mathrm{DRE}, k}^{*}=\Delta^{*}
$$

for all IPO types $\{g, h\}$ and all banks $\{j, k\}$ and that

$$
\delta_{\tau, \eta, j}\left[P_{\tau, \eta, j}^{*}\right]=\delta_{\tau, \eta, k}\left[P_{\tau, \eta, k}^{*}\right]=\Delta_{\tau, \eta}^{*}
$$

for all IPO types $\tau$ and all banks $\{j, k\}$, where $\Delta^{*}\left(\Delta_{\tau, \eta}^{*}\right)$ is the market equilibrium level of downside risk on an IPO type (a $\tau / \eta$ isotype).

We wish to find fundamental offer price $P_{\tau, \eta, \text { EIM }}^{*}$ for each IPO isotype. To begin, the Pricing Constraint implies that

$$
P_{\tau, \beta, \text { EIM }}^{*}=\bar{V}_{\tau, \beta} \forall \tau \text {. }
$$

Equations (25) and (26) then imply that we can pool together all $\tau$ IPOs and rewrite the equation that defines the optimal offer price on a $\{\tau, \alpha\}$ IPO at a given bank (equation (23)) on a market-wide basis, yielding

$$
P_{\tau, \alpha, \mathrm{EIM}}^{*}=P_{\tau, \alpha}: \Delta_{\tau, \alpha}\left[P_{\tau, \alpha}\right]=\frac{\Delta^{*}-\sigma_{\tau, \beta} \Delta_{\tau, \beta}^{*}}{\sigma_{\tau, \alpha}} .
$$


Obviously,

$$
\bar{R}_{\tau, \mathrm{EIM}}^{*}=\bar{R}_{\tau}\left[P_{\tau, \alpha, \mathrm{EIM}}^{*}, P_{\tau, \beta, \mathrm{EIM}}^{*}\right]
$$

Equations (28) and (29) provide the foundation for our empirical test of the EIMH.

We now develop that test.

\section{Testing the EIMH: Method}

If the IPO market is efficient and issuer fundamentals do determine IPO offer prices, then it will be the case that

$$
\bar{R}_{\tau, \mathrm{EIM}}\left[P_{\tau, \alpha, \mathrm{EIM}}^{*}, P_{\tau, \beta, \mathrm{EIM}}^{*}\right]=\bar{R}_{\tau, O}\left[P_{\tau, \alpha, O}^{*}, P_{\tau, \beta, O}^{*}\right]
$$

where $\bar{R}_{\tau, O}$ is the observed average initial return on $\tau$ IPOs and $P_{\tau, \eta, O}^{*}$ is the observed offer price on $\{\tau, \eta\}$ IPOs. So, we propose to test the EIMH by: i) forming portfolios of TEST IPOs; ii) estimating $\bar{R}_{\mathrm{TEST}, \mathrm{EIM}}^{*}$; and iii) seeing if

$$
\left|\bar{R}_{\mathrm{TEST}, \mathrm{EIM}}\left[P_{\mathrm{TEST}, \alpha, \mathrm{EIM}}^{*}, P_{\mathrm{TEST}, \beta, \mathrm{EIM}}^{*}\right]-\bar{R}_{\mathrm{TEST}, O}^{*}\right|<\epsilon,
$$

where $\epsilon$ is a small number.

Suppose that we are estimating $\bar{R}_{\text {TEST,EIM }}^{*}$ with a sample consisting of:

- $A$ TEST/ $\alpha$ IPOs, numbered $a=1 \ldots A$;

- $B$ TEST $/ \beta$ IPOs, numbered $b=1 \ldots B$; and 
- $C$ CONTROL IPOs, numbered $c=1 \ldots C$.

We take our sample of TEST IPOs as fixed and we assume that we measure the market equilibrium level of downside risk with noise. As uncertainty over the market equilibrium level of downside risk will lead to a noisy estimate of $\bar{R}_{\text {TEST,EIM }}^{*}$, we calculate both a point estimate and a confidence interval for $\bar{R}_{\text {TEST,EIM }}^{*}$

Noting that

$$
\bar{R}_{\mathrm{TEST}, \mathrm{EIM}}^{*}=\sigma_{\mathrm{TEST}, \alpha}^{*} \bar{R}_{\mathrm{TEST}, \alpha, \mathrm{EIM}}^{*}+\sigma_{\mathrm{TEST}, \beta}^{*} \bar{R}_{\mathrm{TEST}, \beta, \mathrm{EIM}}^{*}
$$

we estimate $\bar{R}_{\text {TEST,EIM }}^{*}$ by estimating each parameter in equation (31).

To begin, we set $\sigma_{\mathrm{TEST}, \alpha}^{*}$ and $\sigma_{\mathrm{TEST}, \beta}^{*}$ equal to their sample values, implying that

$$
\sigma_{\mathrm{TEST}, \alpha}^{*}=\sigma_{\mathrm{TEST}, \alpha, O}^{*}=\frac{A}{A+B} \quad \text { and } \quad \sigma_{\mathrm{TEST}, \beta}^{*}=\sigma_{\mathrm{TEST}, \beta, O}^{*}=\frac{B}{A+B} .
$$

Now consider $\bar{R}_{\mathrm{TEST}, \beta, \mathrm{EIM}}^{*}$. We assume that banks set $\beta$ IPO offer prices at their maximum feasible value, and hence that a $\beta$ IPO's fundamental offer price equals its observed offer price. It follows that

$$
\bar{R}_{\mathrm{TEST}, \beta, \mathrm{EIM}}^{*}=\bar{R}_{\mathrm{TEST}, \beta, O}^{*} .
$$

The last term of equation (31) is $\bar{R}_{\mathrm{TEST}, \alpha, \mathrm{EIM}}^{*}$, where

$$
\bar{R}_{\mathrm{TEST}, \alpha, \mathrm{EIM}}^{*}=\frac{1}{A} \sum_{1}^{A} \frac{V_{\mathrm{TEST}, a}^{*}-P_{\mathrm{TEST}, a, \mathrm{EIM}}^{*}}{P_{\mathrm{TEST}, a, \mathrm{EIM}}^{*}}
$$


We define $P_{\text {TEST }, a, \text { EIM }}^{*}$ in terms of $P_{\mathrm{TEST}, a, O}^{*}$, with

$$
P_{\mathrm{TEST}, a, \mathrm{EIM}}^{*}=\theta^{*} P_{\mathrm{TEST}, a, O}^{*}
$$

and substitute this expression into equation (28), yielding

$$
P_{\mathrm{TEST}, a, \mathrm{EIM}}^{*}=\theta^{*} P_{\mathrm{TEST}, a, O}^{*}: \Delta_{\mathrm{TEST}, \alpha}\left[\theta \vec{P}_{\mathrm{TEST}, \alpha, O}^{*}\right]=\frac{\Delta^{*}-\sigma_{\mathrm{TEST}, \beta} \Delta_{\mathrm{TEST}, \beta}^{*}}{\sigma_{\mathrm{TEST}, \alpha}},
$$

where $\vec{P}_{\text {TEST }, \alpha, O}^{*}$ is the vector of the offer prices of the sample $\alpha$ IPOs. As above, we set $\sigma_{\mathrm{TEST}, \alpha}$ and $\sigma_{\mathrm{TEST}, \beta}$ equal to their sample values. Given that $P_{\mathrm{TEST}, b, \mathrm{EIM}}^{*}=P_{\mathrm{TEST}, b, O}^{*}$ for all $\beta$ IPOs, it follows that

$$
\Delta_{\mathrm{TEST}, \beta, \mathrm{EIM}}^{*}=\Delta_{\mathrm{TEST}, \beta, O}^{*}=\left|\frac{1}{B} \sum_{1}^{B} R_{\mathrm{TEST}, b} I_{\mathrm{NEG}}\right|,
$$

where

$$
I_{\mathrm{NEG}}= \begin{cases}1, & \text { if } R<0 \\ 0, & \text { if } R \geq 0\end{cases}
$$

The last term we need to estimate is $\Delta^{*}$. If banks do set offer prices equal to fundamental offer prices, then it follows that sample CONTROL IPO offer prices equal fundamental offer prices and hence that $\Delta^{*}=\Delta_{\text {CONTROL }}^{*}$. Consequently, our point estimate of the market level of downside risk is $\Delta_{\mathrm{POINT}}^{*}$, with

$$
\Delta_{\mathrm{POINT}}^{*}=\Delta_{\mathrm{CONTROL}, \mathrm{POINT}}^{*}=\left|\frac{1}{C} \sum_{1}^{C} R_{\mathrm{CONTROL}, c} I_{\mathrm{NEG}}\right| .
$$


Consequently,

$$
\Delta_{\mathrm{TEST}, \alpha, \mathrm{POINT}}^{*}=\frac{\Delta_{\mathrm{CONTROL}, \mathrm{POINT}}^{*}-\sigma_{\mathrm{TEST}, \beta, O} \Delta_{\mathrm{TEST}, \beta, O}^{*}}{\sigma_{\mathrm{TEST}, \alpha, O}} .
$$

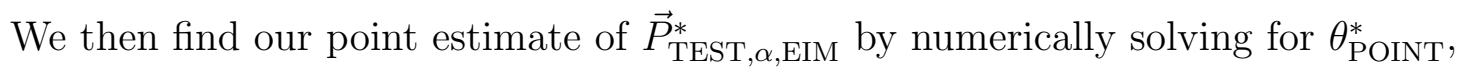
with

$$
\theta_{\mathrm{POINT}}^{*}=\theta:\left|\frac{1}{A} \sum_{1}^{A} \frac{V_{\mathrm{TEST}, a}^{*}-\theta P_{\mathrm{TEST}, a, O}^{*}}{\theta P_{\mathrm{TEST}, a, O}^{*}} I_{\mathrm{NEG}}\right|=\Delta_{\mathrm{TEST}, \alpha, \mathrm{POINT}}^{*}
$$

It follows that

$$
\bar{R}_{\mathrm{TEST}, \alpha, \mathrm{EIM}, \mathrm{POINT}}^{*}=\frac{1}{A} \sum_{1}^{A} \frac{V_{\mathrm{TEST}, a}^{*}-\theta_{\mathrm{POINT}}^{*} P_{\mathrm{TEST}, a, O}^{*}}{\theta_{\mathrm{POINT}}^{*} P_{\mathrm{TEST}, a, O}^{*}}
$$

and that

$$
\bar{R}_{\mathrm{TEST}, \mathrm{EIM}, \mathrm{POINT}}^{*}=\sigma_{\mathrm{TEST}, \alpha, O}^{*} \bar{R}_{\mathrm{TEST}, \alpha, \mathrm{EIM}, \mathrm{POINT}}^{*}+\sigma_{\mathrm{TEST}, \beta, O}^{*} \bar{R}_{\mathrm{TEST}, \beta, O}^{*} .
$$

To construct a confidence interval for our $\bar{R}_{\text {TEST,EIM }}^{*}$ estimates, we use a bootstrap consisting 10,000 trials. In each trial we:

- Draw a bootstrap trial $\xi$ from our CONTROL sample;

- Calculate $\Delta_{\text {CONTROL }, \xi}$ as in equation (35) using the bootstrap trial rather than the original CONTROL sample;

- Compute $\bar{R}_{\mathrm{TEST}, \mathrm{EIM}, \xi}^{*}$ using $\Delta_{\mathrm{CONTROL}, \xi}$ rather than $\Delta_{\mathrm{CONTROL}, \mathrm{POINT}}$. 
We operationalize our EIMH test (equation (30)) by measuring the Expected Absolute Error (EAE) between our estimate of $\bar{R}_{\mathrm{TEST}, \mathrm{EIM}}^{*}$ and $\bar{R}_{\mathrm{TEST}, O}^{*}$, with

$$
\mathrm{EAE}_{\mathrm{TEST}}=\frac{1}{10,000} \sum_{\xi=1}^{10,000}\left|\bar{R}_{\mathrm{TEST}, \mathrm{EIM}, \xi}^{*}-\bar{R}_{\mathrm{TEST}, O}^{*}\right|
$$

We accept the EIMH if

$$
\mathrm{EAE}_{\mathrm{TEST}} \leq \epsilon^{*}
$$

Obviously, choosing an appropriate value for $\epsilon^{*}$ is a matter of judgement (Black (1986) defined an efficient market as "one in which price is within a factor of 2 of value"). And, to the best of our knowledge, there is no alternative theory of IPO average initial returns that provides quantitative predictions against which we can benchmark our analysis. Somewhat arbitrarily, then, we set $\epsilon^{*}$ at $5 \%$.

We have implicitly assumed here that TEST and CONTROL portfolios each consist of a single IPO type as we define an IPO type in our theoretical analysis. We show in the appendix that this test also works when TEST and CONTROL portfolios consist of a blend of pure types (as any IPO type that we can define empirically will inevitably be).

\section{The Sample and IPO Attributes}

We start with a list of all US IPOs in the Thomson Reuters SDC database with offer dates between 1/1/1999 and 12/31/2016. We include an IPO in the sample if:

- SDC provides a non-missing value for the IPO's offer price, closing price, global 
proceeds, gross spread, and CUSIP;

- The IPO's offer price is $\geq \$ 5$;

- The IPO's global proceeds are $\geq \$ 25$ million (in $\$ 2009$ );

- The IPO's gross spread is between $3 \%$ and $12 \%$ (inclusive);

- The IPO's primary exchange is the NYSE, American, or Nasdaq;

- The underwriting bank's pricing technique is reported as Bookbuilding and its offering technique is reported as Firm Commitment/Negotiated Sale;

- The IPO consists of common shares;

- The issuer is not a Closed End Fund, a Trust, or a REIT; and

- The SDC offer date is within 10 days of the issuer's first trading day on CRSP (we match by Ticker).

Our sample consists of 1745 IPOs.

We set an IPO $z$ 's initial return $\left(R_{z}\right)$ equal to

$$
R_{z}=\frac{P_{\mathrm{CLOSE}, \mathrm{z}}-P_{\mathrm{OFFER}, \mathrm{z}}}{P_{\mathrm{OFFER}, \mathrm{z}}},
$$

where an IPO's offer price is from SDC and its closing price is the closing price reported by CRSP on its first trading day.

We limit the sample to IPOs with Global Proceeds of at least $\$ 25$ million in order to eliminate the possibility of our analysis being driven by extreme returns on very small 
IPOs. However, including IPOs with Global Proceeds of less than $\$ 25$ million does not materially alter any of our results.

We sort IPOs into types and isotypes on the basis of the following attributes:

- $\mathrm{BOOM}(B)$ or PBOOM (PB): An IPO with an offer date in 1999 or 2000 (between $1 / 1 / 2001$ and $12 / 31 / 2016)$

- TECH $(T)$ or NTECH (NT): An issuer that is (is not) in a Tech industry as classified by SDC;

- HIGH_PRESTIGE (HP) or LOW_PRESTIGE (LP): An IPO whose lead underwriter is a bank with with a prestige rating $\geq(\nsupseteq) 8.5$ for our entire sample period (the HP banks are Credit Suisse, Deutsche Bank, Goldman Sachs, J.P. Morgan, Merrill Lynch, and Morgan Stanley); ${ }^{17}$

- $\alpha$ or $\beta$ : An IPO with an offer price within or above (below) its initial offer price range.

An IPO type is defined as a bundle of attributes, and an IPO is of a given type if it has all of the attributes that define that type. So, for example, BOOM/TECH IPOs are TECH IPOs with an offer date in 1999 or 2000. Each IPO type consists of an $\alpha$ and a $\beta$ isotype. We summarize our Sample selection criteria and IPO attribute definitions in Table 1.

[Insert Table 1 about here]

\footnotetext{
${ }^{17}$ We take our underwriter prestige ratings from Jay Ritter's website
} 


\section{Testing the EIMH: Results}

The principal challenge facing any theory of IPO average initial returns is to explain: i) the extremely high $\bar{R}$ on Tech IPOs during the DotCom Boom; and ii) the substantial time-series variation in the $\bar{R}$ of Tech and NonTech IPOs over the Boom and the PostBoom period. We therefore examine the validity of the EIMH by using the method we devise in Section III to see if the combination of the optimal IPO pricing rule we derive in Section II and issuer fundamentals enables us to accurately and precisely predict the quantitative magnitude of this cross-sectional and time-series variation in average initial returns.

To do so, we carry out two sets of tests. In the first set, we sort IPOs into types that capture the cross-sectional and time-series variation in $\bar{R}$ on the basis of issuer/IPO characteristics alone. In this set of tests we are implicitly assuming that underwriter characteristics do not play a role in determining an IPO's offer price. So, in the second set of tests, we split each IPO type we define in the first set into two types on the basis of the prestige of the IPO's underwriter. Consider each set of tests in turn.

\section{A. Issuer Fundamentals and Average Initial Returns}

We begin by defining four TEST portfolios: BOOM/TECH (B/T), BOOM/NTECH (B/NT), PBOOM/TECH (PB/T), and PBOOM/NTECH (PB/NT). We also create two CONTROL portfolios: BOOM and PBOOM. We report summary statistics on these IPO types and their associated $\alpha$ and $\beta$ isotypes in Table 2 .

\section{[Insert Table 2 about here]}

We then estimate $\bar{R}_{\text {TEST,EIM }}^{*}$ for each TEST portfolio. To do so, we estimate the 
market equilibrium level of downside risk for each cross-sectional TECH and NTECH pair using a common CONTROL portfolio consisting of all IPOs from the other time period. So, for example, we use the PBOOM portfolio as the CONTROL for our estimate of $\bar{R}_{\mathrm{TEST}, \mathrm{EIM}}^{*}$ for B/T and B/NT IPOs. Consequently, our estimate of $\bar{R}_{\mathrm{TEST}, \mathrm{EIM}}^{*}$ for one period's TECH IPOs is completely independent of our estimate of $\bar{R}_{\text {TEST,EIM }}^{*}$ for that period's NTECH IPOs.

Carrying out this analysis, we obtain the following results (summarized in Table 3):

- B/T: The observed $\bar{R}$ on B/T IPOs is $76.74 \%$. We find that i) $\bar{R}_{\mathrm{B} / \mathrm{T}, \mathrm{EIM}}^{*}=75.30 \%$; ii) the $95 \%$ confidence interval for $\bar{R}_{\mathrm{B} / \mathrm{T}, \mathrm{EIM}}^{*}$ is $\{72.30 \%, 79.14 \%\}$; and that iii) $\mathrm{EAE}_{\mathrm{B} / \mathrm{T}}$ $=1.90 \%$;

- B/NT: The observed $\bar{R}$ on B/NT IPOs is $28.55 \%$. We find that: i) $\bar{R}_{\mathrm{B} / \mathrm{NT}, \mathrm{EIM}}^{*}=$ $26.74 \%$; ii) the $95 \%$ confidence interval for $\bar{R}_{\mathrm{B} / \mathrm{NT}, \mathrm{EIM}}^{*}$ is $\{25.71 \%, 27.74 \%\}$; and that iii) $\mathrm{EAE}_{\mathrm{B} / \mathrm{NT}}=1.80 \%$.

- $\mathrm{PB} / \mathrm{T}$ : The observed $\bar{R}$ on PB/T IPOs is $17.07 \%$. We find that: i) $\bar{R}_{\mathrm{PB} / \mathrm{T}, \mathrm{EIM}}^{*}=$ $20.92 \%$; ii) the $95 \%$ confidence interval for $\bar{R}_{\mathrm{PB} / \mathrm{T}, \mathrm{EIM}}^{*}$ is $\{17.73 \%, 25.06 \%\}$; and that iii) $\mathrm{EAE}_{\mathrm{PB} / \mathrm{T}}=3.85 \%$;

- $\mathrm{PB} / \mathrm{NT}$ : The observed $\bar{R}$ on PB/NT IPOs is $11.76 \%$. We find that: i) $\bar{R}_{\mathrm{PB} / \mathrm{NT}, \mathrm{EIM}}^{*}=$ $10.97 \%$; ii) the $95 \%$ confidence interval for $\bar{R}_{\mathrm{PB} / \mathrm{NT} \text {,EIM }}^{*}\{9.45 \%, 13.10 \%\}$; and that iii) $\mathrm{EAE}_{\mathrm{PB} / \mathrm{NT}}=1.01 \%$.

In short, we find that the EIMH produces extremely accurate estimates of the magnitude of the observed average initial return on both TECH and NTECH IPOs in both the 
BOOM and PBOOM period. Furthermore, these $\bar{R}_{\mathrm{TEST}, \mathrm{EIM}}^{*}$ estimates are very precise (as one can see from the plots of their confidence intervals in Figure 1). Consequently, the expected absolute error between $\bar{R}_{\text {TEST,EIM }}^{*}$ and the observed average initial return on a TEST portfolio falls below our $5 \%$ target for all four TEST portfolios.

\section{[Insert Table 3 about here]}

\section{[Insert Figure 1 about here]}

\section{B. Underwriter Prestige and Average Initial Returns}

In our theoretical analysis we assume that all banks use the same IPO pricing rule in equilibrium despite a considerable body of empirical evidence suggesting that high prestige banks use a different pricing rule than low prestige banks (see, for example, Carter and Manaster (1990), Carter, Dark, and Singh (1998), and Loughran and Ritter (2004)). So, to explore the validity of this assumption, we split each IPO type we analyze above into a HP and a LP variant TEST/PREST, PREST $\in\{$ HP, LP $\}$, where TEST/PREST contains all IPOs of that type underwritten by a bank with a prestige rating of PREST (as defined in Section IV). We then estimate $\bar{R}_{\text {TEST/PREST,EIM }}^{*}$ for each variant of each IPO type separately as above.

We report summary statistics for each TEST/PREST porfolio in Table 3. Consistent with Loughran and Ritter (2004), we find that $\bar{R}_{\mathrm{TEST} / \mathrm{HP}, O}^{*}>\bar{R}_{\mathrm{TEST} / \mathrm{LP}, O}^{*}$ for each IPO type.

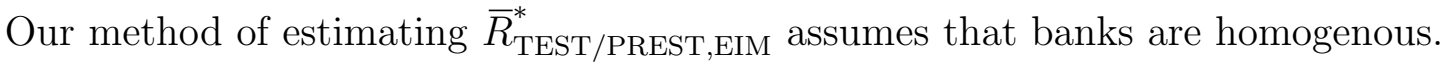
So, if the $\bar{R}$ differences we observe arise because high prestige banks use a pricing rule that 
results in greater underpricing (all else equal) than the pricing rule used by low prestige banks, then we would expect to find that $\bar{R}_{\mathrm{TEST} / \mathrm{HP}, \mathrm{EIM}}^{*}<\bar{R}_{\mathrm{TEST} / \mathrm{HP}, O}^{*}$ and $\bar{R}_{\mathrm{TEST} / \mathrm{LP}, \mathrm{EIM}}^{*}>\bar{R}_{\mathrm{TEST} / \mathrm{LP}, O}^{*}$. If instead banks do provide a homogenous underwriting service (implying that any differences in $\bar{R}$ arise from differences in issuer fundamentals across HP and LP banks), then we would expect to find that $\bar{R}_{\mathrm{TEST} / \mathrm{PREST} \text {,EIM }}^{*}=\bar{R}_{\mathrm{TEST} / \mathrm{PREST}, O}^{*}$ for all IPO types.

We report the results of this analysis in Table 3 and plot the confidence intervals for our $\bar{R}_{\mathrm{TEST} / \mathrm{PREST} \text {,EIM }}^{*}$ estimates in Figure 2. As in our first set of tests, we find that $\bar{R}_{\text {TEST/HP,EIM }}^{*}$ provides an accurate and precise estimate of the empirical magnitude of $\bar{R}_{\mathrm{TEST} / \mathrm{PREST}, O}^{*}$ for all IPO types. To illustrate, we calculate that $\bar{R}_{\mathrm{EIM}}^{*}$ is $99.80 \%$ for B/T/HP IPOs and $55.68 \%$ for B/T/LP IPOs. The observed $\bar{R}$ on these IPOs is $106.36 \%$ and $54.14 \%$ respectively. These results therefore suggest that high prestige and low prestige underwrites do use the same pricing rule. ${ }^{18}$

\section{[Insert Figure 2 about here]}

\section{What Explains the Variation in IPO Average Initial Returns?}

IPO average initial returns do vary tremendously along both time-series and cross-sectional dimensions. Yet, the optimal IPO pricing rule that the EIMH produces enables us to accurately and precisely predict the quantitative magnitude of this variation. Consequently, these results imply that: i) banks do use the optimal IPO pricing rule that

\footnotetext{
${ }^{18}$ It is true that the EAE for B/T/HP IPOs of $6.57 \%$ is very slightly higher than the $5 \%$ threshold we have chosen for accepting the EIMH. We therefore classify the $\mathrm{B} / \mathrm{T} / \mathrm{HP}$ case as a Borderline acceptance of the EIMH.
} 
the EIMH yields; and that ii) the substantial cross-sectional and time-series variation we observe in IPO average initial returns is driven by the combination of this pricing rule and the cross-sectional and time-series variation in issuer fundamentals.

\section{Conclusion}

The IPO market consists of sophisticated banks who intermediate between sophisticated issuers on the one hand and sophisticated investors on the other in an environment characterized by informational frictions. We conjecture that the sensible way to model this market is to assume that it consists of fully rational optimizing agents. ${ }^{19}$ In this case: i) banks will devise the optimal underwriting method given the informational frictions that characterize the market; and ii) an IPO's offer price will be determined entirely by the combination of the pricing rule implied by that underwriting method and issuer fundamentals. We label this conjecture the Efficient IPO Market Hypothesis (EIMH), and we test the EIMH by seeing if banks do set offer prices in this manner.

Our analysis finds that block-booking is the optimal underwriting method and that block-booking banks set offer prices such that the downside risk on an IPO given its optimal offer price equals the market equilibrium level of downside risk. To calculate the average initial return that this pricing rule implies for a portfolio of TEST IPOs, we first estimate the market equilibrium level of downside risk using a completely independent

${ }^{19}$ That is, as Thaler (2016) would put it, we assume that all of the agents in our model are Econs. Thaler (2016) argues in favor of rejecting the Efficient Markets Hypothesis itself on the grounds that models with agents that behave as Econs are completely implausible as models of how markets actually function. The success of our Econ-based model of the IPO market provides a counter-example to this critique. 
CONTROL portfolio. We then adjust TEST IPO offer prices by a scalar such that the downside risk on the TEST portfolio given the scalar-adjusted offer prices equals the market equilibrium level of downside risk. The average initial return on TEST IPOs in an efficient market is then the average initial return on those IPOs with the scalar-adjusted offer prices.

The biggest challenge for any IPO pricing theory - especially a rational optimizing agent theory such as ours - is to explain the extremely high average initial return on Tech IPOs during the DotCom Boom and the dramatic variation in Tech and NonTech IPO underpricing over time. We therefore test the EIMH by seeing if the optimal pricing rule our analysis yields enables us to accurately and precisely predict the quantitative magnitude of this cross-sectional and time-series variation in average initial returns. We find that it does. To illustrate: our analysis implies that the average initial return on Tech IPOs during the DotCom Boom of 1999/2000 in an efficient market is $75.30 \%$, while the observed average initial return on these IPOs is $76.74 \%$.

To the best of our knowledge, the EIMH we develop here (building upon Gondat-Larralde and James (2008)) is the only theory that yields precise quantitative predictions for the time-series and cross-sectional variation in IPO average initial returns. The strong empirical support that we find for the predictions of this theory therefore implies that banks do use the optimal underwriting method to take firms public and hence that IPO offer prices (and so average initial returns) are determined entirely by issuer fundamentals given the pricing rule implied by that underwriting method. This finding in turn suggests that the agency conflict and/or behavioral factors that are the focus of much of the post-DotCom Boom research on IPOs do not play any significant role in determining 
IPO offer prices.

We conclude that the IPO market is efficient.

\section{Appendix}

\section{A. Proofs of the Propositions}

Proposition 1: Within the constraints imposed by its choice of a valid underwriting method, a bank maximizes the expected offer price (minimizes expected underpricing) of its IPOs so as to maximize expected fees.

If the market is in equilibrium, then

$$
\Omega^{*}=S \bar{P}+\bar{\lambda} \text {. }
$$

Solving for $S$ using equation (42) and rewriting the bank's market value (equation (2)) yields

$$
M=\sum_{t} \gamma^{t} \frac{1}{Q_{U}}\left(\Omega^{*}+\bar{P}-\bar{V}+\left(\sigma_{Y} \kappa_{Y}+\sigma_{N} \kappa_{N}\right)(\bar{V}-\bar{P})\right)
$$

Taking the derivative of equation (43) with respect to $\bar{P}$, we find that

$$
\frac{\partial \pi_{\beta}}{\partial \bar{P}}=\sum_{t} \gamma^{t} \frac{1}{Q_{U}}\left(1-\sigma_{Y} \kappa_{Y}-\sigma_{N} \kappa_{N}\right)>0
$$

That is, a bank's market value increases as the expected offer price on its IPOs increases (holding the price of underwriting services constant). 
Proposition 5: A market equilibrium price of underwriting services exist.

We assume that the market is in a Nash equilbrium in which each bank $j$ simultaneously chooses a price of underwriting services $\omega_{j}$ such that $\omega_{j}=\Omega^{*}$ for all $j$. To solve for the equilibrium, we assume that all banks $g, g \neq z$, choose $\omega_{g}^{*}=\Omega_{\mathrm{CAN}}^{*}$, where $\Omega_{\mathrm{CAN}}^{*}$ is a candidate $\Omega^{*}$. Bank $z$ can choose any $\omega_{z}$, with $\omega_{z}=\Omega_{\mathrm{CAN}}^{*}-\zeta$. Since bank market values increase with $\Omega, \Omega^{*}$ will equal the highest value of $\Omega$ such that $z$ chooses $\zeta$ equal to 0 .

Given that the variability of initial returns will make it difficult for an issuer to detect differences in the cost of underwriting services across banks absent a great deal of data, we assume that issuers begin with a prior that the market is in equilibrium and learn each bank's true cost of underwriting over time. To capture this intuition in a tractable manner, we assume that $z$ 's probability of winning a mandate in period $t$ is a function of $\zeta$ and $t$, with

$$
\phi_{w, z, t}= \begin{cases}\frac{1}{Q_{U}}, & \text { if } \quad \zeta=0, \\ \frac{1}{Q_{U}}, & \text { if } t<t_{\mathrm{LONG}}, \\ \phi_{w, z, \mathrm{LONG}}[\zeta], & \text { if } t \geq t_{\mathrm{LONG}} \text { and } \zeta>0 .\end{cases}
$$

We assume that

$$
\frac{\partial \phi_{w, z, \mathrm{LONG}}}{\partial \zeta}>0 \text { and } \frac{\partial^{2} \phi_{w, z, \mathrm{LONG}}}{\partial \zeta^{2}}<0 .
$$

We further assume that $t_{\mathrm{LONG}}$ and the investor discount parameter are such that $Y$ investors place essentially no weight on $z$ 's higher market share after $t_{\mathrm{LONG}}$ when deciding 
whether to lemon-dodge. In other words, $z$ has to set offer prices assuming a market share of $Q_{u}$. Consequently, z can only lower its cost of underwriting services by lowering its gross spread and not by increasing offer prices.

Bank z's market value equals

$$
M_{z}=\sum_{1}^{t_{\mathrm{LONG}}-1} \gamma_{u}^{t} \frac{1}{Q_{u}} \bar{\pi}_{z}\left[\Omega_{\mathrm{CAN}}^{*}, \zeta\right]+\sum_{t_{\mathrm{LONG}}}^{\infty} \gamma_{u}^{t} \phi_{w, z, \mathrm{LONG}}[\zeta] \bar{\pi}_{z}\left[\Omega_{\mathrm{CAN}}^{*}, \zeta\right]
$$

$$
=\Gamma_{\mathrm{SHORT}} \frac{1}{Q_{u}} \bar{\pi}_{z}\left[\Omega_{\mathrm{CAN}}^{*}, \zeta\right]+\Gamma_{\mathrm{LONG}} \phi_{w, z, \mathrm{LONG}}[\zeta] \bar{\pi}_{z}\left[\Omega_{\mathrm{CAN}}^{*}, \zeta\right]
$$

where the $\Gamma$ terms represent the present discounted value multipliers. Obviously,

$$
\frac{\partial \bar{\pi}_{z}}{\partial \zeta}=-1 \text { and } \frac{\partial \bar{\pi}_{z}}{\partial \Omega_{\mathrm{CAN}}^{*}}>0
$$

Taking the derivative of $M_{z}$ wrt $\zeta$, we find that

$$
\frac{\partial M_{z}}{\partial \zeta}=\frac{\Gamma_{\mathrm{SHORT}}}{Q_{u}} \frac{\partial \bar{\pi}_{z}}{\partial \zeta}+\Gamma_{\mathrm{LONG}} \frac{\partial \phi_{w, z, \mathrm{LONG}}}{\partial \zeta} \pi_{z}+\Gamma_{\mathrm{LONG}} \phi_{w, z, \mathrm{LONG}} \frac{\partial \pi_{z}}{\partial \zeta}
$$

The first and third terms of equation (46) are less than 0 , so $\partial M_{z} / \partial \zeta<0$ for a sufficiently low $\Omega_{\mathrm{CAN}}^{*}$. Taking the derivative of $\partial M_{z} / \partial \zeta$ shows that

$$
\frac{\partial^{2} M_{z}}{\partial \zeta \partial \Omega_{\mathrm{CAN}}^{*}}=\Gamma_{\mathrm{LONG}} \frac{\partial \phi_{w, z, \mathrm{LONG}}}{\partial \zeta} \frac{\partial \pi_{z}}{\partial \Omega_{\mathrm{CAN}}^{*}}>0
$$

It follows that there exists a unique maximum $\Omega_{\mathrm{CAN}}^{*}$ such that $\zeta=0$. This value of $\Omega$ is the market equilibrium price of underwriting services $\Omega^{*}$. 


\section{B. Testing the EIMH with Blended Portfolios}

Our test of the EIMH requires fairly large TEST and CONTROL portfolios as it involves estimating the downside risk of an IPO type's return distribution. In practice, then, any IPO type that we use in our empirical analysis will be broad (for example, Tech IPOs during the DotCom Boom) and will therefore inevitably consist of a blend of pure IPO types as we define them in our theoretical analysis. So, we now briefly show that the test we develop in Section III will work with blended TEST and CONTROL portfolios.

For simplicity, suppose that CONTROL IPOs consist of two pure types BC1 and $\mathrm{BC} 2$ in unknown proportions $\mu_{\mathrm{BC} 1}$ and $\mu_{\mathrm{BC} 2}$ and that TEST IPOs also consist of two pure types BT1 and BT2 in unkown proportions $\mu_{\mathrm{BT} 1}$ and $\mu_{\mathrm{BT} 2}$.

We estimate $\Delta^{*}$ using CONTROL IPOs. If $\Delta_{\mathrm{BC} 1}^{*}=\Delta_{\mathrm{BC} 2}^{*}=\Delta^{*}$, then it is obvious that

$$
\Delta_{\mathrm{CONTROL}, O}^{*}=\mu_{\mathrm{BC} 1} \Delta_{\mathrm{BC} 1}^{*}+\mu_{\mathrm{BC} 2} \Delta_{\mathrm{BC} 2}^{*}=\Delta^{*} .
$$

Hence, using a blended CONTROL sample to estimate the equilibrium level of downside risk (equation (35)) does not pose any problems for our analysis.

Turning to TEST IPOs, there will be a $\theta^{*}$ such that

$$
\Delta^{*}=\mu_{\mathrm{BT} 1} \Delta_{\mathrm{BT} 1}\left[\theta^{*} P_{\mathrm{BT} 1, \alpha, O}^{*}\right]+\mu_{\mathrm{BT} 2} \Delta_{\mathrm{BT} 2}\left[\theta^{*} P_{\mathrm{BT} 2, \alpha, O}^{*}\right],
$$

where $\theta^{*}$ is now the uniform swing needed in TEST IPO offer prices to equalize downside risk across TEST and CONTROL IPOs (we drop $\beta$ IPO offer prices from equation (48) as they are fixed by the Pricing Constraint). We can therefore estimate $\theta^{*}$ as above. 
If banks do block book then $P_{\mathrm{BT} 1, \alpha, O}^{*}=P_{\mathrm{BT} 1, \alpha, \mathrm{EIM}}^{*}$ and $P_{\mathrm{BT} 2, \alpha, O}^{*}=P_{\mathrm{BT} 2, \alpha, \mathrm{EIM}}^{*}$, implying that $\bar{R}_{\mathrm{TEST}, O}^{*}=\bar{R}_{\mathrm{TEST}, \mathrm{EIM}}^{*}$. In this case we will find that EAE $\mathrm{E}_{\mathrm{TEST}}$ is small and so will (correctly) accept the EIMH. If, on the other hand, banks systematically set TEST IPO offer prices below (or above) their fundamental offer prices, then we will find that $\theta^{*} \neq 1$ and hence that $\bar{R}_{\mathrm{TEST}, O}^{*} \neq \bar{R}_{\mathrm{TEST}, \mathrm{EIM}}^{*}$. In this case we will find that EAE $\mathrm{E}_{\mathrm{TEST}}$ is large and so will (correctly) reject the EIMH. We therefore believe that our EIMH test will enable us to detect any systematic deviation between observed offer prices and fundamental offer prices even when the CONTROL and TEST IPO portfolios we use consist of a blend of pure IPO types.

\section{The MaxiMin Effect}

In our theory: i) each IPO type consists of a low value $\beta$ isotype and a high value $\alpha$ isotype; ii) issuers have MaxiMin preferences; and iii) banks set offer prices to equalize downside risk across IPO types (not isotypes). Banks therefore set $\beta$ IPO offer prices at their maximum feasible level and set $\alpha$ IPO offer prices at the level that brings about downside risk equalization across IPO types. It follows that $\beta$ IPO offer prices are higher and $\alpha$ IPO offer prices are lower than they would be if banks set offer prices to equalize downside risk across each isotype independently. We denote the gap between the observed $\bar{R}$ on TEST $/ \eta$ IPOs and what that $\bar{R}$ would be if isotypes were priced independently $\left(\bar{R}_{\mathrm{TEST}, \eta, \mathrm{IND}}^{*}\right)$ as the MaxiMin Effect or MME, with

$$
\mathrm{MME}_{\mathrm{TEST}, \eta}^{*}=\bar{R}_{\mathrm{TEST}, \eta, O}^{*}-\bar{R}_{\mathrm{TEST}, \eta, \mathrm{IND}}^{*}
$$


To gauge the magnitude of the MME, we first estimate $\bar{R}_{\mathrm{TEST}, \eta, \mathrm{IND}}^{*}$ for each isotype of the $\mathrm{B} / \mathrm{T}, \mathrm{B} / \mathrm{NT}, \mathrm{PB} / \mathrm{T}$, and $\mathrm{PB} / \mathrm{NT}$ portfolios we define in Section $\mathrm{V}$. To do so, we use the method we devise in Section III to estimate $\bar{R}_{\text {TEST,EIM }}^{*}$ (modified as needed to take account of the fact that we carrying out this estimate for a single isotype), setting the equilibrium level of downside risk for each isotype equal to the observed downside risk on the appropriate CONTROL portfolio from Section V. We then use equation (49) to compute the point estimate and confidence interval for $\mathrm{MME}_{\mathrm{TEST}, \eta}^{*}$ for each isotype. We report these MME estimates in Table C.1.

We find that the MME is non-trivial for $\beta$ IPOs during the Boom. The MME pushes the $\bar{R}$ on $\mathrm{B} / \mathrm{T} / \beta$ IPOs from $20.26 \%$ to its observed value of $5.71 \%$ and the $\bar{R}$ on $\mathrm{B} / \mathrm{NT} / \beta$ IPOs from $11.05 \%$ to its observed value of $0.77 \%$. That said, we note that our B/NT/ $\beta$ sample consists of only 13 IPOs, so obviously the observed $\bar{R}$ on these IPOs is a very noisy estimate of its true value.

We also find that the MME is close to zero for $\alpha$ IPOs during the Boom and for all IPOs in the PostBoom period. For example, the MME is only $4.22 \%$ for $\mathrm{B} / \mathrm{T} / \alpha$ IPOs and $-3.85 \%$ for $\mathrm{PB} / \mathrm{T} / \beta$ IPOs.

One implication of this analyis is that, while MME effects are non-trivial in some cases, the gap between $\bar{R}$ on $\alpha$ and $\beta$ IPOs would be substantial even if each isotype were priced independently. It follows that the within type cross-sectional variation in average initial returns is mostly down to the variation in $\alpha$ and $\beta$ IPO fundamentals rather than to the MME effect.

This analysis also suggests that the MME did reduce issuer risk during the Boom by substantially increasing an issuer's offer price in the event of a poor project value 
Table C.1: The Magnitude of the MaxiMin Effect

Each IPO type consists of a low value $\beta$ isotype (empirically: an IPO with its offer price below its initial offer price range) and a high value $\alpha$ isotype (empirically: an IPO with its offer price within or above its initial offer price range). Due to issuer MaxiMin preferences, banks set the offer price on a $\beta$ isotype at its maximum feasible level and so set the offer price on an $\alpha$ isotype at the level required to equalize downside risk across IPO types. Consequently, $\beta$ IPO offer prices are higher and $\alpha$ IPO offer prices are lower than they would be if banks set offer prices independently for each isotype. We denote the gap between the observed average initial return $\left(\bar{R}_{\text {TEST }, \eta, O}^{*}\right)$ on TEST $/ \eta$ IPOs $(\eta \in\{\alpha, \beta\})$ and what that $\bar{R}$ would be if isotypes were priced independently $\left(\bar{R}_{\text {TEST }, \eta, \text { IND }}^{*}\right)$ as the MaxiMin Effect (MME), with MME TEST,$\eta^{*}=\bar{R}_{\text {TEST }, \eta, O}^{*}-\bar{R}_{\text {TEST }, \eta, \text { IND }}^{*}$. In this table we report for each sample isotype: i) $\bar{R}_{\mathrm{TEST}, \eta, O}^{*}$; ii) $\bar{R}_{\mathrm{TEST}, \eta, \mathrm{IND}}^{*}$; iii) MME $\mathrm{MEST}, \eta^{*}$; and iv) the 95\% confidence interval for MME $\mathrm{MEST}, \eta^{*}$. See Table 1 for portfolio definitions and Table 2 for summary statistics.

\begin{tabular}{lcccc}
\hline Isotype & $\bar{R}_{\mathrm{TEST}, \eta, O}^{*}(\%)$ & $\bar{R}_{\mathrm{TEST}, \eta, \mathrm{IND}}^{*}(\%)$ & MME $(\%)$ & $95 \% \mathrm{CI}$ \\
\hline $\mathrm{B} / \mathrm{T} / \alpha$ & 82.51 & 78.29 & 4.22 & $\{1.63,6.68\}$ \\
$\mathrm{B} / \mathrm{T} / \beta$ & 5.71 & 20.26 & -14.55 & $\{-12.67,-16.36\}$ \\
$\mathrm{B} / \mathrm{NT} / \alpha$ & 32.39 & 29.11 & 3.28 & $\{2.34,4.23\}$ \\
$\mathrm{B} / \mathrm{NT} / \beta$ & 0.77 & 11.05 & -10.28 & $\{-8.52,-11.95\}$ \\
$\mathrm{PB} / \mathrm{T} / \alpha$ & 20.90 & 23.33 & -2.41 & $\{-5.43,0.12\}$ \\
$\mathrm{PB} / \mathrm{T} / \beta$ & 4.21 & 8.06 & -3.85 & $\{-5.83,-2.13\}$ \\
$\mathrm{PB} / \mathrm{NT} / \alpha$ & 14.37 & 12.83 & 1.53 & $\{0.00,3.00\}$ \\
$\mathrm{PB} / \mathrm{NT} / \beta$ & 3.05 & 4.35 & -1.30 & $\{-2.97,0.10\}$ \\
\hline
\end{tabular}

realization during the IPO process. Furthermore, since only a small proportion of projects received a poor value realization during the Boom, this substantial MME boost to $\beta$ offer prices came at a cost of only a small MME reduction in $\alpha$ offer prices. Hence, our assumption that issuers have MaxiMin preferences is not implausible. 


\section{References}

Benveniste, L. and P. Spindt (1989). "How investment bankers determine the offer price and allocation of new issues". Journal of Financial Economics 24, 343-361.

Benveniste, L. and W. Wilhelm (1990). "A comparative analysis of IPO proceeds under alternative regulatory environments". Journal of Financial Economics 28, 173-207.

Black, F. (1986). "Noise". Journal of Finance 41(3), 528-543.

Brown, D. and S. Kovbasyuk (2016). "Key investors in IPOs". Paris December 2015 Finance Meeting EUROFIDAI - AFFI.

Butler, A. W., M. Keefe, and R. Kieschnick (2014). "Robust determinants of IPO underpricing and their implications for IPO research". Journal of Corporate Finance 27(C), 367-383.

Carter, R. and S. Manaster (1990). "Initial public offerings and underwriter reputation". Journal of Finance 45(4), 1045-1067.

Carter, R. B., F. H. Dark, and A. K. Singh (1998). "Underwriter reputation, initial returns, and the long-run performance of IPO stocks". Journal of Finance 53(1), 285-311.

Cornelli, F. and D. Goldreich (2001). "Bookbuilding and strategic allocation". Journal of Finance 56, 2337-2369.

Goldstein, M., P. Irvine, and A. Puckett (2011). "Purchasing IPOs with commissions". Journal of Financial and Quantitative Analysis 46, 1193-1225. 
Gondat-Larralde, C. and K. James (2008). "IPO pricing and share allocation: The importance of being ignorant". Journal of Finance 63, 449-478.

Grullon, G., S. Underwood, and J. Weston (2014). "Comovement and investment banking networks". Journal of Financial Economics 113, 1-73.

Hanley, K. W. (1993). "The underpricing of initial public offerings and the partial adjustment phenomenon". Journal of Financial Economics 34(2), 231-250.

Jagannathan, R., A. Jirnyi, and A. Sherman (2015). "Share auctions of initial public offerings: Global evidence". Journal of Financial Intermediation 24, 283-311.

Jenkinson, T., H. Jones, and F. Suntheim (2018). "Quid pro quo? What factors influence IPO allocations and pricing". Journal of Finance 73(5), 2303-2341.

Kang, A. and R. Lowery (2014). "The pricing of IPO services and issues: Theory and estimation". The Review of Corporate Finance Studies 2, 188-234.

Kenney, R. and B. Klein (1983). "The economics of block booking". Journal of Law and Economics 26, 497-540.

Krigman, L. and W. Jeffus (2016). "IPO pricing as a function of your investment banks' past mistakes: The case of facebook". Journal of Corporate Finance 38, 335-334.

Ljungqvist, A. and W. Wilhelm (2003). "IPO pricing in the dot-com bubble". Journal of Finance 58, 723-752.

Loughran, T. and J. Ritter (2002). "Why don't issuers get upset about leaving money on the table in IPOs?". Review of Financial Studies 15, 413-444. 
Loughran, T. and J. Ritter (2004). "Why has IPO underpricing changed over time?". Financial Management, 5-37.

Nimalendran, M., J. R. Ritter, and D. Zhang (2007). "Do today's trades affect tomorrow's IPO allocations?". Journal of Financial Economics 84(1), 87-109.

Reuter, J. (2006). "Are IPO allocations for sale? evidence from mutual funds". Journal of Finance 61(5), 2289-2324.

Ritter, J. and I. Welch (2002). "A review of IPO activity, pricing and allocations". Journal of Finance 57, 1795-1827.

Thaler, R. H. (2016). "Behavioral economics: past, present, and future". American Economic Review 106(7), 1577-1600. 
Table 1: Sample, IPO Attributes, and Variable Definitions

Starting with a list of all US IPOs in the Thomson Reuters SDC database with offer dates between 1/1/1999 and 12/31/2016, we include an IPO in the sample if: i) SDC provides a non-missing value for the IPO's offer price, closing price, global proceeds, gross spread, and CUSIP; ii) The IPO's offer price is $\geq \$ 5$; iii) The IPO's global proceeds are $\geq \$ 25$ million (in $\$ 2009$ ); iv) The IPO's gross spread is between $3 \%$ and $12 \%$ (inclusive); v) The IPO's primary exchange is the NYSE, American, or Nasdaq; vi) The underwriting bank's pricing technique is reported as Bookbuilding and its offering technique is reported as Firm Commitment/Negotiated Sale; vii) The IPO consists of common shares; viii) The issuer is not a Closed End Fund, a Trust, or a REIT; and ix) The SDC offer date is within 10 days of the issuer's first trading day on CRSP (we match by Ticker). Our sample consists of 1745 IPOs. We match underwriters with a prestige rating from Jay Ritter's website. We sort IPOs into types and isotypes on the basis of the following attributes:

\begin{tabular}{|c|c|}
\hline Attribute/Variable & Definition \\
\hline $\mathrm{BOOM}(B)$ or PBOOM $(\mathrm{PB})$ : & $\begin{array}{l}\text { An IPO with an offer date during the DotCom } \\
\text { Boom of 1999/2000 (between } 1 / 1 / 2001 \text { and } 12 / 31 / 2016 \text { ); }\end{array}$ \\
\hline TECH $(T)$ or NTECH $(\mathrm{NT})$ : & The issuer is (is not) in a tech industry as classified by SDC; \\
\hline HIGH_PRESTIGE (HP) or LOW_PRESTIGE (LP): & $\begin{array}{l}\text { An IPO whose lead underwritter is a bank with a prestige } \\
\text { rating } \geq(\nsupseteq) 8.5 \text { for our entire sample period } \\
\text { (HP banks are: Credit Suisse, Deutsche Bank, Goldman Sachs, } \\
\text { J.P. Morgan, Merrill Lynch, and Morgan Stanley); }\end{array}$ \\
\hline$\alpha$ or $\beta$ : & $\begin{array}{l}\text { An IPO with a final offer price that is within or above (below) } \\
\text { its initial offer price range; }\end{array}$ \\
\hline Global Proceeds: & Global Proceeds (from SDC) in $\$ 2009$ millions; \\
\hline Initial Return: & $\left(P_{\text {CLOSE }}-P_{\text {Offer }}\right) / P_{\text {OfFER }}$ \\
\hline $\mathrm{P}_{\mathrm{CLOSE}}$ : & An IPO firm's closing price on its offer date (from CRSP); \\
\hline POFFER: & An IPO's offer price (from SDC). \\
\hline
\end{tabular}


Table 2: Summary Statistics On IPO Types

We sort IPOs into types and isotypes. An IPO type is defined as a bundle of attributes (see Table 1 for attribute definitions), and an IPO is of a given type if it has all of the attributes that define that type. So, for example, BOOM/TECH IPOs are TECH IPOs with an offer date in 1999 or 2000. Each IPO type consists of an $\alpha$ and a $\beta$ isotype, where $\alpha(\beta)$ IPOs are IPOs with an offer price within or above (below) their initial offer price range. For each IPO type and isotype, we report: i) the number of IPOs of that type in our sample (Obs); ii) the observed average initial return $\left(\bar{R}_{O}^{*}\right)$; iii) the standard deviatiation of initial returns (StDev); and iv) mean global proceeds ( $\overline{\text { GP }}$ ) in $\$ 2009$.

\begin{tabular}{|c|c|c|c|c|c|c|c|c|c|c|c|c|}
\hline \multirow[b]{2}{*}{ Type } & \multicolumn{4}{|c|}{ All } & \multicolumn{4}{|c|}{$\alpha$ IPOs } & \multicolumn{4}{|c|}{$\beta$ IPOs } \\
\hline & Obs & $\bar{R}_{O}^{*}(\%)$ & StDev & $\overline{\mathrm{GP}}$ & Obs & $\bar{R}_{O}^{*}(\%)$ & StDev & $\overline{\mathrm{GP}}$ & Obs & $\bar{R}_{O}^{*}(\%)$ & StDev & $\overline{\mathrm{GP}}$ \\
\hline Sample & 1745 & 33.46 & 63.67 & 193.11 & 1434 & 39.90 & 68.34 & 194.36 & 311 & 3.79 & 12.17 & 187.32 \\
\hline BOOM (B) & 613 & 68.33 & 93.08 & 160.62 & 562 & 74.13 & 94.95 & 162.11 & 51 & 4.45 & 18.73 & 144.13 \\
\hline BOOM/TECH (B/T) & 506 & 76.74 & 97.64 & 136.40 & 468 & 82.51 & 99.15 & 136.21 & 38 & 5.71 & 20.73 & 138.75 \\
\hline $\mathrm{BOOM} / \mathrm{TECH} / / \mathrm{HP}(\mathrm{B} / \mathrm{T} / \mathrm{HP})$ & 219 & 106.36 & 118.83 & 192.32 & 207 & 112.12 & 119.63 & 185.62 & 12 & 7.05 & 20.42 & 307.89 \\
\hline BOOM/TECH/LP (B/T/LP) & 287 & 54.14 & 69.9 & 93.73 & 261 & 59.02 & 71.19 & 97.03 & 26 & 5.09 & 21.25 & 60.68 \\
\hline BOOM/NTECH/LP (B/NT/LP) & 57 & 25.06 & 45.69 & 97.1 & 47 & 29.82 & 48.82 & 89.47 & 10 & 2.66 & 11.45 & 132.99 \\
\hline PBOOM (PB) & 1132 & 14.58 & 23.41 & 210.7 & 872 & 17.84 & 25.16 & 215.15 & 260 & 3.67 & 10.46 & 195.79 \\
\hline PBOOM/TECH $(\mathrm{PB} / \mathrm{T})$ & 601 & 17.07 & 26.79 & 145.26 & 463 & 20.90 & 28.73 & 156.47 & 138 & 4.21 & 11.95 & 107.63 \\
\hline PBOOM/TECH/HP (PB/T/HP) & 370 & 21.07 & 28.34 & 193.03 & 289 & 25.65 & 29.81 & 208.06 & 81 & 4.73 & 12.67 & 139.4 \\
\hline PBOOM/TECH/LP (PB/T/LP) & 231 & 10.67 & 22.72 & 68.73 & 174 & 13.03 & 25.00 & 70.78 & 57 & 3.47 & 10.91 & 62.48 \\
\hline PBOOM/NTECH (PB/NT) & 531 & 11.76 & 18.50 & 284.77 & 409 & 14.36 & 19.84 & 281.57 & 122 & 3.05 & 8.47 & 295.52 \\
\hline
\end{tabular}


Table 3: Average Initial Returns in an Efficient IPO Market

In an efficient IPO market a bank sets offer prices to equalize downside risk at the market equilibrium level across IPO types (where an IPO's downside risk equals its expected return setting all positive return realizations to zero). To estimate the average intial return on a TEST portfolio of IPOs in an efficient market, we set the market equilibrium level of downside risk equal to the downside risk on an independent CONTROL portfolio (estimated using a bootstrap). Then, we adjust TEST IPO offer prices by a scalar such that the downside risk on TEST IPOs given the scalar-adjusted offer prices equals the market equilibrium level of downside risk. The average initial return on the TEST portfolio in an efficient IPO market is then the average initial return computed with the scalar-adjusted offer prices. For each TEST portfolio, we report: i) the CONTROL portfolio we use to estimate the market equilibrium level of downside risk; ii) the observed average initial return on that TEST portfolio $\left(\bar{R}_{\text {TEST }, O}^{*}\right)$; iii) our point estimate of the average intial return on TEST IPOs in an efficient IPO market $\left(\bar{R}_{\text {TEST,EIM }}^{*}\right)$; iv) the $95 \%$ confidence interval for $\bar{R}_{\text {TEST,EIM }}^{*}$ v) the expected absolute error (EAE) between our estimate of $\bar{R}_{\text {TEST,EIM }}^{*}$ and $\bar{R}_{\text {TEST }, O}^{*}$; and vi) whether or not we accept the Efficient IPO Market Hypothesis (EIMH). We accept the EIMH if EAE $\leq 5 \%$. See Table 1 for IPO type definitions, Table 2 for summary statistics, and the text for details of the method we use to estimate $\bar{R}_{\text {TEST,EIM }}^{*}$.

\begin{tabular}{lcccccc}
\hline TEST & CONTROL & $\bar{R}_{\text {TEST }, O}^{*}(\%)$ & $\bar{R}_{\text {TEST,EIM }}^{*}(\%)$ & $95 \%$ CI & EAE $(\%)$ & Accept EIMH? \\
\hline B/T & PBOOM & 76.74 & 75.30 & $\{72.30,79.14\}$ & 1.90 & Accept \\
B/NT & PBOOM & 28.55 & 26.74 & $\{25.71,27.74\}$ & 1.80 & Accept \\
PB/T & BOOM & 17.07 & 20.92 & $\{17.73,25.06\}$ & 3.85 & Accept \\
PB/NT & BOOM & 11.76 & 10.97 & $\{9.45,13.10\}$ & 1.01 & Accept \\
B/T/HP & PBOOM & 106.36 & 99.80 & $\{95.91,103.60\}$ & 6.57 & Borderline \\
B/T/LP & PBOOM & 54.14 & 55.68 & $\{52.42,59.69\}$ & 1.95 & Accept \\
B/NT/HP & PBOOM & 32.52 & 29.77 & $\{28.83,30.77\}$ & 2.75 & Accept \\
B/NT/LP & PBOOM & 25.06 & 24.12 & $\{23.06,25.38\}$ & 0.98 & Accept \\
PB/T/HP & BOOM & 21.07 & 24.78 & $\{21.17,30.07\}$ & 3.73 & Accept \\
PB/T/LP & BOOM & 10.67 & 14.50 & $\{11.96,17.57\}$ & 3.85 & Accept \\
PB/NT/HP & BOOM & 11.86 & 11.15 & $\{9.48,13.46\}$ & 1.01 & Accept \\
PB/NT/LP & BOOM & 11.58 & 10.64 & $\{9.22,12.39\}$ & 1.05 & Accept \\
\hline
\end{tabular}


Figure 1: Average Initial Returns in an Efficient IPO Market

We sort sample IPOs into four TEST portfolios and we plot each portfolio's observed average initial return and the distribution of our estimate of that average initial return in an efficient IPO market $\left(\bar{R}_{\text {TEST,EIM }}^{*}\right)$. Our TEST portfolios are: BOOM/TECH (B/T); BOOM/NTECH (B/NT); PBOOM/TECH (PB/T); and PBOOM/NTECH (PB/NT). See Table 2 for summary statistics on each IPO type and Table 3 for a description of how we calculate average initial returns in an efficient IPO market. The observed average initial return for each TEST portfolio is indicated by the dashed horizontal line and the solid horizontal lines indicate the 95\% confidence interval of our $\bar{R}_{\text {TEST,EIM }}^{*}$ estimate.

\section{Average Initial Return}

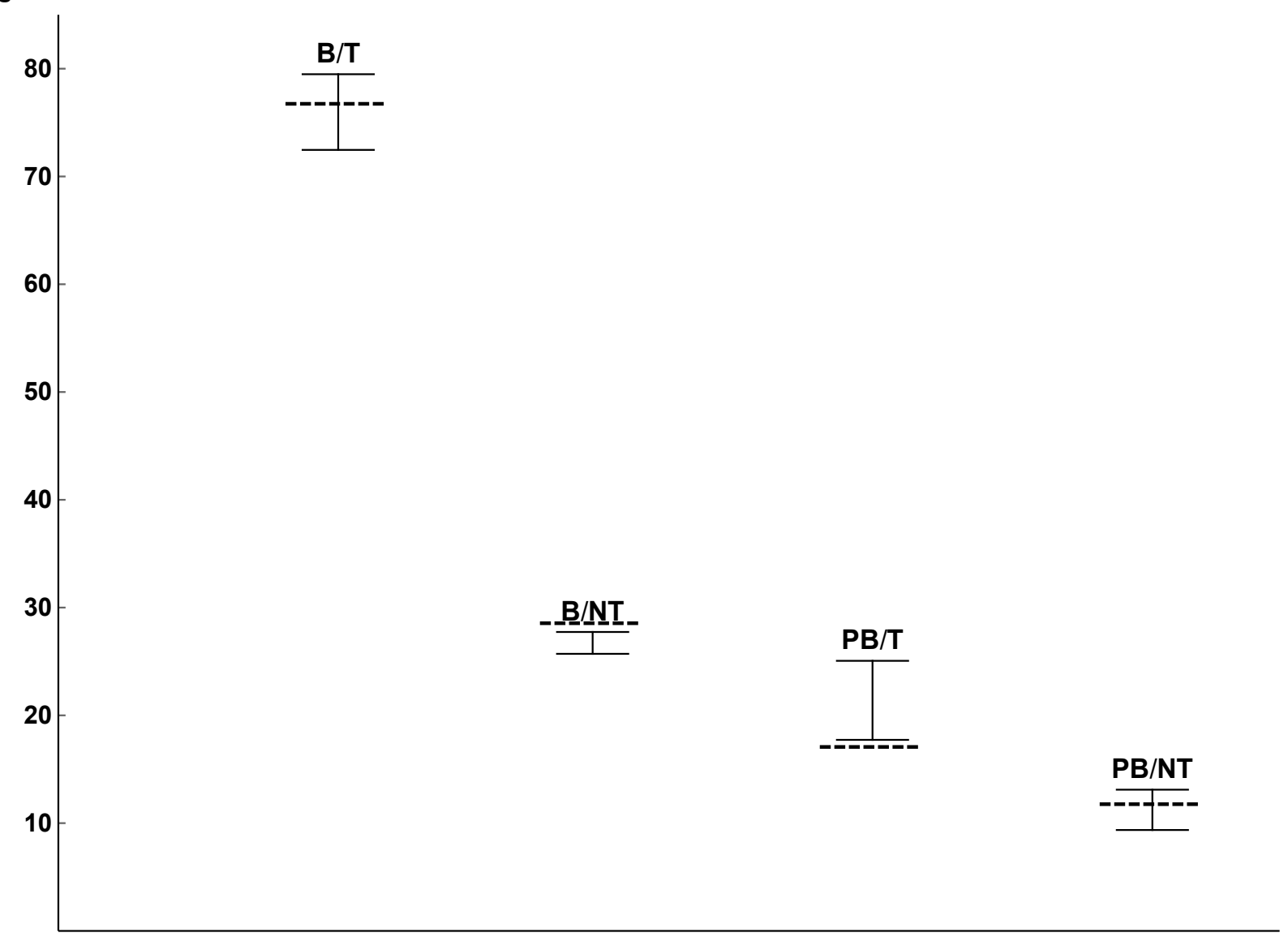


Figure 2: Underwriter Prestige, Issuer Funamentals, and Average Initial Returns We divide each IPO type in Table 1 into a HP and a LP variant, with the HP (LP) variant consiting of all IPOs of that type underwritten by a HIGH_PRESTIGE (LOW_PRESTIGE) bank. We plot the observed average initial return and the distribuiton of our estimate of the average initial return in an efficient IPO market implied by issuer fundamentals alone $\left(\bar{R}_{\text {TEST,EIM }}^{*}\right)$ for each variant. See Table 2 for summary statistics on each IPO type and Table 3 for a description of how we calculate $\bar{R}_{\text {TEST,EIM. }}^{*}$ The observed average initial return for each TEST portfolio is indicated by the dashed horizontal line and the solid horizontal lines indicate the 95\% confidence interval of our $\bar{R}_{\text {TEST,EIM }}^{*}$ estimate.

Average Initial Return
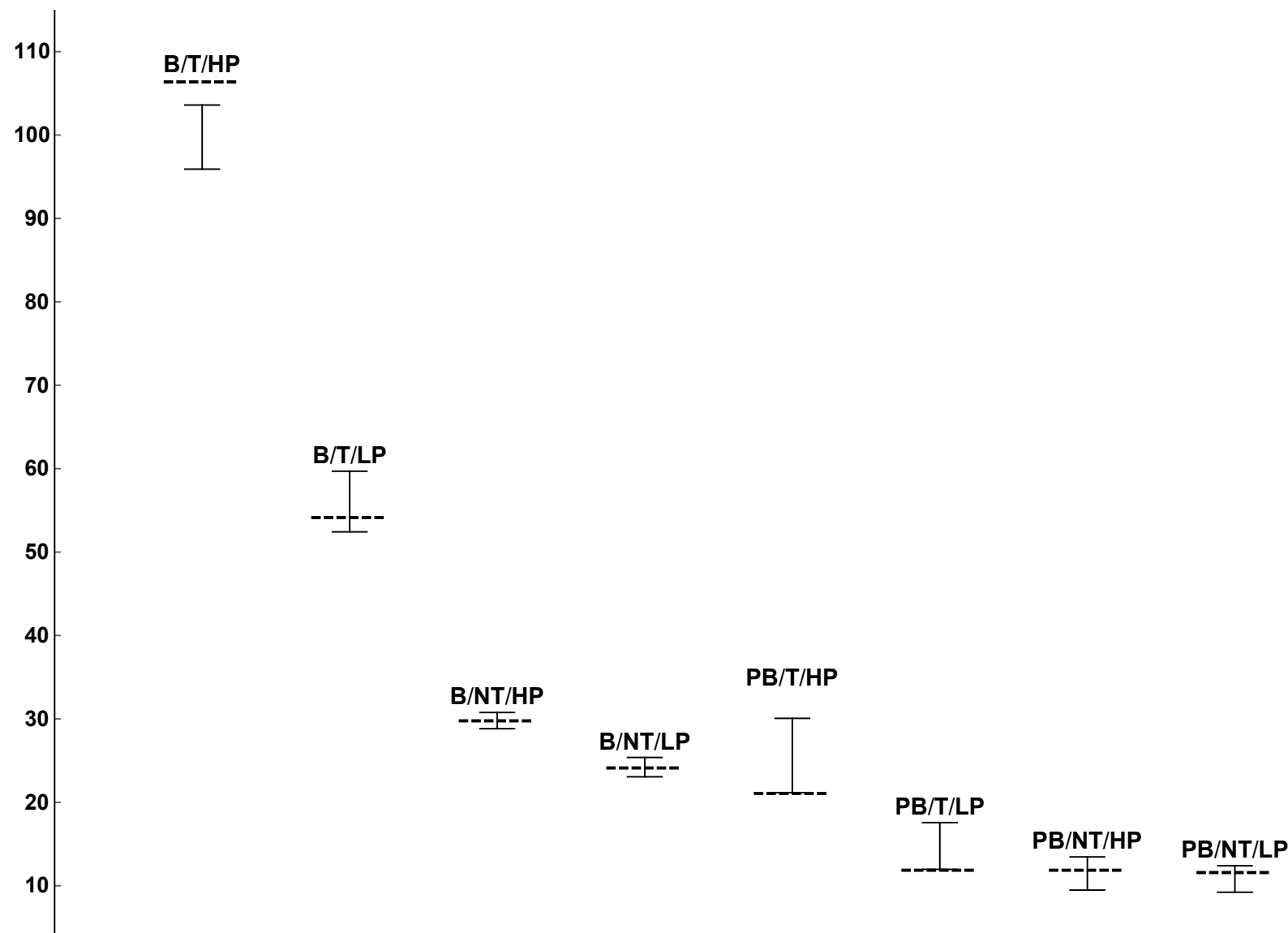